\title{
A linkage map of transcribed single nucleotide polymorphisms in rohu (Labeo rohita) and QTL associated with resistance to Aeromonas hydrophila
}

Nicholas Robinson ${ }^{1,3^{*}}$, Matthew Baranski ${ }^{1}$, Kanta Das Mahapatra², Jatindra Nath Saha², Sweta Das², Jashobanta Mishra ${ }^{2}$, Paramananda Das ${ }^{2}$, Matthew Kent ${ }^{4}$, Mariann Arnyasi ${ }^{4}$ and Pramoda Kumar Sahoo ${ }^{2}$

\begin{abstract}
Background: Production of carp dominates world aquaculture. More than 1.1 million tonnes of rohu carp, Labeo rohita (Hamilton), were produced in 2010. Aeromonas hydrophila is a bacterial pathogen causing aeromoniasis in rohu, and is a major problem for carp production worldwide. There is a need to better understand the genetic mechanisms affecting resistance to this disease, and to develop tools that can be used with selective breeding to improve resistance. Here we use a $6 \mathrm{~K}$ SNP array to genotype 21 full-sibling families of L. rohita that were experimentally challenged intra-peritoneally with a virulent strain of $A$. hydrophila to scan the genome for quantitative trait loci associated with disease resistance.
\end{abstract}

Results: In all, 3193 SNPs were found to be informative and were used to create a linkage map and to scan for QTL affecting resistance to $A$. hydrophila. The linkage map consisted of 25 linkage groups, corresponding to the number of haploid chromosomes in L. rohita. Male and female linkage maps were similar in terms of order, coverage (1384 and 1393 CM, respectively) and average interval distances (1.32 and 1.35 CM, respectively). Forty-one percent of the SNPs were annotated with gene identity using BLAST (cut off E-score of 0.001). Twenty-one SNPs mapping to ten linkage groups showed significant associations with the traits hours of survival and dead or alive $(P<0.05$ after Bonferroni correction). Of the SNPs showing significant or suggestive associations with the traits, several were homologous to genes of known immune function or were in close linkage to such genes. Genes of interest included heat shock proteins (70, 60, 105 and "small heat shock proteins"), mucin (5b precursor and 2), lectin (receptor and CD22), tributyltin-binding protein, major histocompatibility loci (I and II), complement protein component c7-1, perforin 1, ubiquitin (ligase, factor e4b isoform 2 and conjugation enzyme e2 c), proteasome subunit, T-cell antigen receptor and lymphocyte specific protein tyrosine kinase.

Conclusions: A panel of markers has been identified that will be validated for use with both genomic and markerassisted selection to improve resistance of $L$. rohita to A. hydrophila.

Keywords: Labeo rohita, Single nucleotide polymorphism, Transcribed sequences, Linkage map, Quantitative trait loci, Aeromonas hydrophila resistance

\footnotetext{
* Correspondence: nicholas.robinson@nofima.no

${ }^{1}$ Breeding and Genetics, Nofima, PO Box 5010, 1432 Ås, Norway

${ }^{3}$ Biological Sciences, Flinders University, Bedford Park, Australia

Full list of author information is available at the end of the article
} 


\section{Background}

Carp is one of the world's most important group of aquaculture species, with production of Rohu carp (Labeo rohita Hamilton) accounting for around 1.2 million tonnes in 2010 [1]. Production occurs in India, Bangladesh, Myanmar, Laos and Thailand and most of the fish is consumed within these countries. A selective breeding program established by the Central Institute of Freshwater Aquaculture in Bhubaneswar India has a focus on increasing the growth rate of the fish and has been supplying a genetically improved variety of $L$. rohita called Jayanti rohu to the farmers and hatcheries of various States in India since 1992. A 17\% percent higher average growth rate per generation was achieved after 4 generations of selective breeding [2] and eight generations of selection have now been completed with a similar selection response. Rohu is efficiently grown in earthen ponds, however disease prevention in this environment is difficult, and mortality and growth loss from disease in India is high.

Aeromonas hydrophila is an endemic motile pathogenic bacteria causing haemorrhaging and ulceration when fish are stressed as reviewed by [3]. A. hydrophila is widespread and difficult to control and treat as there are no effective drugs or vaccines. The disease aeromoniasis caused by $A$. hydrophila infection is a world-wide problem affecting many fish species. Significant additive genetic variation affecting the survival of rohu exposed to experimental challenge tests with $A$. hydrophila has been found [4]; however, rohu is not an ideal model species for studying the genetics of disease resistance. Mortalities occur quickly (sometimes within 30 hours after experimental challenge, [4]) and differences in the challenge infection procedure are believed to affect expression of the genetic potential to survive this disease. Even so, one generation of divergent selection based on challenge test data has been shown to result in significantly higher average rates of survival $(73.3 \pm 3.3 \%$ versus $16.7 \pm 3.3 \%$ ), blood phagocyte respiratory burst activity, serum myeloperoxidase activity and ceruloplasmin level in resistant compared to susceptible line rohu [5]. A major limitation to selective breeding is the inability to directly test highly valuable broodstock by challenging them to the disease.

Knowledge about causative genes, or markers associated with genes affecting disease resistance, could be used to increase the rate of genetic improvement through selective breeding. Markers for disease resistance have been detected and applied to the selective breeding of other teleost species [6-8], but little knowledge exists for $L$. rohita, and resources needed to develop such tests (eg. linkage maps for polymorphic markers) have been lacking. RNAsequencing has recently been performed to characterise the transcriptomes of selected lines of L. rohita, and to concurrently identify SNPs and indels in transcribed genes [9]. Quantitative analysis of RNA-seq data revealed that lines of rohu selected for resistance to A. hydrophila showed higher fold naïve expression and allele frequency differences for a number of genes with putative functions affecting immune response when compared to lines selected for susceptibility to A. hydrophila. These genes included major histocompatibility class I loci, heat shock proteins 30, 70 and 90, glycoproteins, serum lectin and galactoside-binding soluble lectin. Ceruloplasmin is 4.58 times more highly expressed in resistant than in susceptible line rohu carp that were selected based on family challenge test survival to $A$. hydrophila [10]. SNP polymorphisms at superoxide dismutase 3 , an antioxidant enzyme, has also been found to be associated with resistance to A. hydrophila in the freshwater mussel Hyriopsis cumingii [11].

Here we genotype full-sibling families using an Illumina iSelect array containing SNPs found in transcribed genes, in order to produce a genetic linkage map of the L. rohita genome and simultaneously scan the genome of challenge tested families for variation associated with resistance to $A$. hydrophila.

\section{Results}

\section{Linkage map}

A conversion rate of $87.2 \%$ meant that the SNP-array used in this study contained 5,232 of the original 6,000 assays (within the manufacturers specified tolerances). After automatic and manual clustering, 3242 markers $(62 \%)$ fell into the usable "SNP" marker category, with the remainder being fails, monomorphic or low callconfidence markers. Approximately $2 \%$ of markers did not segregate according to Mendelian expectations in some of the 21 families genotyped $(P<0.05$, after Bonferroni correction).

In total, 3193 informative SNP markers mapped to 25 linkage groups (Additional files 1 and 2). The female and male maps contained 3008 and 3071 SNP markers respectively and 2886 SNP markers were informative for both maps.

The female linkage map covered $1384 \mathrm{cM}$ with an average interval of $1.32 \mathrm{cM}$ and a maximum interval of $12.7 \mathrm{cM}$ (Table 1). The length of the 25 linkage groups ranged from 45.4 to $75.9 \mathrm{cM}$ and the number of markers varied from 83 to 216 per group. The genome length estimate for the female was $1407 \mathrm{cM}$ resulting in coverage of $99 \%$ of the genome within $1 \mathrm{cM}$ of a framework marker.

The male linkage map covered 1393.5 cM with an average interval of $1.35 \mathrm{cM}$ and a maximum interval of $37.1 \mathrm{cM}$ (Table 1). The length of the linkage groups ranged from 34.2 to $87.6 \mathrm{cM}$ and the number of markers varied from 87 to 220 per group. The genome length 
Table 1 Comparison of map intervals between male and female $L$. rohita linkage maps

\begin{tabular}{|c|c|c|c|c|c|}
\hline \multirow[b]{2}{*}{ LG } & \multirow[b]{2}{*}{ SNPs } & \multicolumn{2}{|c|}{ Maximum distance (cM) } & \multicolumn{2}{|c|}{ Total distance (cM) } \\
\hline & & Female & Male & Female & Male \\
\hline 1 & 126 & 3.7 & 2.2 & 51 & 55.3 \\
\hline 2 & 100 & 8.6 & 3.5 & 58.1 & 40.9 \\
\hline 3 & 105 & 5.7 & 3.8 & 55.4 & 51.6 \\
\hline 4 & 140 & 4.5 & 3.8 & 53 & 57.9 \\
\hline 5 & 152 & 4.4 & 2.9 & 54.5 & 49.2 \\
\hline 6 & 120 & 12.7 & 8.5 & 75.9 & 52.4 \\
\hline 7 & 234 & 4 & 2.5 & 58.5 & 58.3 \\
\hline 8 & 123 & 11.1 & 4.8 & 62 & 58.4 \\
\hline 9 & 124 & 2.5 & 3.7 & 49.6 & 53.4 \\
\hline 10 & 130 & 3.1 & 6.2 & 45.4 & 50.4 \\
\hline 11 & 116 & 5.8 & 5.5 & 49 & 57.4 \\
\hline 12 & 100 & 4.8 & 23.6 & 60.9 & 71.5 \\
\hline 13 & 89 & 8.8 & 3.4 & 60.1 & 34.2 \\
\hline 14 & 101 & 4 & 37.1 & 46.2 & 87.6 \\
\hline 15 & 158 & 5.2 & 3.4 & 49.7 & 63.4 \\
\hline 16 & 96 & 5.5 & 3.8 & 57.2 & 53.7 \\
\hline 17 & 163 & 3.8 & 3.6 & 66.5 & 48.8 \\
\hline 18 & 139 & 6.8 & 5.7 & 55.7 & 62.9 \\
\hline 19 & 113 & 7.5 & 3.6 & 52.4 & 55.6 \\
\hline 20 & 148 & 5.2 & 7.2 & 48.3 & 59.3 \\
\hline 21 & 135 & 4.1 & 2.5 & 48.6 & 56.4 \\
\hline 22 & 152 & 4.8 & 3 & 54.3 & 44.4 \\
\hline 23 & 122 & 5.2 & 7 & 58.6 & 54.2 \\
\hline 24 & 103 & 10 & 10 & 60.4 & 58.5 \\
\hline 25 & 104 & 7.6 & 4.7 & 52.7 & 57.8 \\
\hline
\end{tabular}

LG, linkage group; SNPs, -number of markers on sex-average map.

estimate for the male was $1416 \mathrm{cM}$ resulting in coverage of $99 \%$ of the genome within $1 \mathrm{cM}$ of a framework marker.

Little difference was detected between the total lengths and map distances between the male and female specific maps (Table 1). The male map was $9 \mathrm{cM}$ longer than the female map, 122 female informative markers were linked in the female map but unlinked in the male map, while 185 male informative markers were linked on the male map but not the female map.

Overall, $L$. rohita linkage groups 1-25 corresponded with $D$. rerio chromosome numbers $15,24,17,16,19$, $21,3,1,13,23,12,9,25,4,2,11,7,8,14,22,6,5,20$, 10 and 18 respectively. There was strong correspondence between the order of genes within linkage groups for L. rohita and the order of the same genes within chromosomes in Danio rerio (zebra fish, Additional file 3) although some differences in the ordering of blocks of genes within $L$. rohita linkage groups, compared to $D$. rerio chromosomes, were observed. For instance, the gene order from $0-47$ cM of LG18 in L. rohita corresponds to much the same order as from 55,178,337 bp - 589,315 bp of chromosome 8 in $D$. rerio, except that the block of genes between positions 2,781,136 and 8,043,460 bp on chromosome 8 in $D$. rerio run from $48.9-56.6 \mathrm{cM}$ in L. rohita linkage group 18, indicating that there has been a rearrangement at the end of this linkage group/chromosome. The similarity between $L$. rohita and $D$. rerio gene sequences was on average $87 \%( \pm 0.3 \% \mathrm{SE}$, average L. rohita transcript length of $155 \mathrm{bp})$. Forty-one percent of the mapped L. rohita SNPs were annotated with gene identity using BLAST (cut off E-score of 0.001).

\section{Challenge tests}

The most susceptible and resistant $20 \%$ of animals from each of the challenge tested families were sampled for DNA extraction and a random set of these selected for genotyping giving an overall mean survival 12.19 \pm 9.89 SD hours post $A$. hydrophila challenge. The spread of hours survival ranged from 2 to 26 hours. Plots of hours survival for the animals genotyped within each of the 21 full-sibling family groups that were challenged and sampled are shown in Additional file 4: Figure S1.

\section{Genetic parameters associated with A. hydrophila resistance}

Significant effects of tank and pedigree on hours of survival (Table 2) and dead or alive traits (not shown) were detected. Heritability of hours of survival and dead or alive traits were low ( 0.05 and 0.07 respectively) but significant $(0.02-0.16$ and $0.02-0.20$ lower and upper 95\% confidence intervals for the two traits respectively). The genetic correlation between the hours of survival and dead or alive traits (0.79) was positive, high and significant (0.59 and 0.94 lower and upper $95 \%$ confidence intervals respectively).

\section{Quantitative trait loci (QTL) associated with resistance to A. hydrophila}

The quality control steps excluded all markers whose inheritance was non-Mendelian and all individuals who could be excluded with parentage analysis, leaving 3193 markers and 965 phenotyped and genotyped progeny of 21 sires and 21 dams for association analysis. Although tank and pedigree (family) were found to be significant fixed effects, their inclusion in the model for QTL analysis did not affect the SNPs found to be associated with either trait or the overall level of significance for the associations. Results for the simplest model (without fixed effects) are therefore presented here.

Half-sib regression interval mapping analysis detected one genome-wide significant QTL for hours of survival on LG15 (dam-based) and five suggestive QTL both 
Table 2 MCMCglmm analysis under an animal model of hours of survival after experimental challenge to $A$. hydrophila

\begin{tabular}{cccccc}
\hline \multicolumn{5}{c}{$95 \%$ confidence limits } \\
\hline Parameter & Mean & Lower & Upper & Effective sample & $P$-value \\
\hline Genetic structure & & & & \\
animal & 7.2 & 1.7 & 15.3 & 1220 & \\
ID & 24.9 & 1.1 & 66.9 & 359 & \\
units & 60.9 & 16.1 & 89.5 & 369.2 & \\
(Intercept) & 0.1 & -2.9 & 2.9 & 1519 & 0.961 \\
tank & 5.6 & 3.3 & 7.7 & 1400 & $<7 \mathrm{e}-04^{* * *}$ \\
ped2008F12 & 7.3 & 3.3 & 11 & 1613 & $<7 \mathrm{e}-04^{* * *}$ \\
ped2008F13 & 4.7 & -0.2 & 9.4 & 1400 & 0.056 \\
ped2008F21 & 7.6 & 3.7 & 11.0 & 1400 & $<7 \mathrm{e}-04^{* * *}$ \\
ped2008F22 & 7.9 & 4.4 & 12 & 1400 & $<7 \mathrm{e}-04^{* * *}$ \\
ped2008F24 & -4.6 & -9.1 & 0.8 & 1400 & 0.067 \\
ped2008F29 & 0.9 & -2.7 & 5 & 1400 & 0.63 \\
ped2008F34 & -2.7 & -9.1 & 3.2 & 1400 & 0.379 \\
ped2008F38 & -8.5 & -16.7 & -0.8 & 1400 & 0.043 \\
ped2008F41 & 12.2 & 8.2 & 16.1 & 1400 & $<7 \mathrm{e}-04^{* * *}$ \\
ped2008F44 & -1.9 & -20.1 & 16.5 & 1400 & 0.826 \\
ped2008F49 & 1.4 & -3.4 & 6.0 & 1400 & 0.553 \\
\hline
\end{tabular}

Tank and family (ped2008F12 - ped2008F49) were fitted as fixed effects. Mean, mean of posterior distribution. ${ }^{*}, P<0.05$. ${ }^{* *}, P<0.01$. ${ }^{* *}, P<0.001$.

hours of survival and the binary dead/alive trait (Table 3). In only one case was a suggestive QTL detected for both traits on the same linkage group (LG3). In all cases we were able to infer that two of the seven analysed parents were segregating for the QTL.

The genome-wide association studies (GWAS) detected many regions with suggestive QTL for A. hydrophila resistance for the two traits $(P<0.001$ before Bonferroni correction, Tables 4 and 5). Twenty-one SNPs mapping to ten linkage groups $(4,7,14,15,18-21,23,24)$, and covering possibly twelve distinct regions in total, showed

Table 3 Summary of suggestive and significant QTL detected using GridQTL half-sib regression analysis

\begin{tabular}{lccccc}
\hline LG & Analysis (Sire/Dam) & Trait & Pos & F-stat & Segregation \\
\hline 3 & Dam & Dead/alive & $22 \mathrm{cM}$ & $3.39^{*}$ & (A \& C) \\
3 & Dam & Hours & $22 \mathrm{cM}$ & $3.57^{*}$ & (A \& C) \\
7 & Sire & Dead/alive & $2 \mathrm{cM}$ & $3.42^{*}$ & (A \& D) \\
14 & Dam & Dead/alive & $39 \mathrm{cM}$ & $3.26^{*}$ & (A \& E) \\
15 & Dam & Hours & $29 \mathrm{cM}$ & $4.68^{* *}$ & (C \& G) \\
19 & Dam & Dead/alive & $13 \mathrm{cM}$ & $2.81^{*}$ & (A \& C) \\
23 & Sire & Hours & $0 \mathrm{cM}$ & $3.23^{*}$ & (C \& D)
\end{tabular}

*Chromosome-wide significance.

**Genome-wide significance.

LG, linkage group. Pos, position on LG in cM. Segregation, families showing segregation for the QTL. significant associations with the trait hours of survival $(P<0.05$ after Bonferroni correction, Figures $1 \mathrm{~A}, \mathrm{C}$ and $\mathrm{E}$ and $2 \mathrm{~A}, \mathrm{C}$ and $\mathrm{E})$. Of these, SNPs mapping to linkage groups 7, 20 and 23 were significant at $P<0.01$ level after Bonferroni correction for some tests and one SNP mapping to $0 \mathrm{cM}$ on linkage group 23 (93296_256 with homology to loc795887 uncharacterised protein from $D$. rerio) was significant at $P<0.001$ after Bonferroni correction for the GRAMMA test (Figure 3). Linkage group 23 corresponds to chromosome 20 of the D. rerio genome (Additional file 3). Genes of potential interest in terms of immune function mapping to this region of LG23 included dermatin sulphate epimerase (SNP 55156_84, Additional file 1).

Twelve SNPs mapping to six linkage groups $(6,14,18$, 19,20 and 23, and covering possibly seven distinct regions in total, showed significant associations with the trait dead or alive $(P<0.05$ after Bonferroni correction, Figures $1 \mathrm{~B}, \mathrm{D}$ and $\mathrm{F}$ and $2 \mathrm{~B}, \mathrm{D}$ and $\mathrm{F}$ ). One of these SNPs (4460_67 at $47.1 \mathrm{cM}$ on LG14, with no known homology) was significant at $P<0.01$ after Bonferroni correction. A SNP mapping to this same position shares homology to chaperonin (HSP60) containing subunit 2 (132709_550, Additional file 1).

Of the SNPs with suggestive and significant associations with hour of mortality and alive or dead traits, several showed homology to genes of known immune function (Table 6). SNP 55086_181 at $37.3 \mathrm{cM}$ on LG1 (hours of survival and dead or alive traits) showed homology to small heat shock protein, 87896_2052 at 46.9 cM on LG6 (dead or alive) to complement protein component c7-1, 31265_40 at 54.9 cM on LG8 (hours of survival) to CD22 antigen, 113696_50 at 43.9 cM on LG14 (hours of survival) to perforin 1, 110434_333 at 26.7 cM on LG15 (hours of survival) to t-cell antigen receptor alpha chain c region, 115737_104 at 23.8 cM on LG 16 (hours of survival) to mucin-5b precursor, 111569 63 at $23.8 \mathrm{cM}$ on LG19 (hours of survival and dead or alive) to tributyltin (tbt)-binding protein and 554_399 at 23.2 cM on LG22 (hours of survival) to dipeptidyl-peptidase 7 (Tables 4, 5 and 6). Two contigs coding for mucin-5b precursor were found to be on average 3.8 times more highly expressed in resistant line than susceptible line fish (interquartile range 1.28, Figure 4), with contig_115737 (containing SNP 115737_104) around 5 times more differentially expressed in resistant line fish.

In addition to these noteworthy SNPs, some regions containing SNPs showing suggestive or significant associations with hour of mortality and/or alive or dead traits also contained candidate genes of interest with respect to disease resistance (Table 6). SNPs with homology to complement c4 (52852_1499) and heat shock protein 105kd (53470_163) map approximately $5 \mathrm{cM}$ from small heat shock protein 55086_181 on LG1 (Additional file 1) which 
Table 4 Suggestive and significant QTL for trait hours of survival after challenge with $A$. hydrophila detected using PLINK (QFAM) and GenAbel (FASTA and GRAMMA) analyses in 21 L. rohita families

\begin{tabular}{|c|c|c|c|c|c|c|c|c|c|}
\hline LG & Pos & SNP & Test & $\mathrm{N}$ & Effect & Stat & $P$-value & Sig & GenelD \\
\hline 1 & 37.3 & 55086_181 & FASTA & 963 & $-2.22(0.82)$ & 7.32 & 0.0068 & & Small heat shock \\
\hline 1 & 37.3 & 55086_181 & GRAMMA & 963 & $-1.18(0.56)$ & 4.47 & 0.00538 & & Small heat shock \\
\hline 2 & 43.9 & 121615_93 & QFAM & 1021 & & -1.449 & 0.00675 & & \\
\hline 2 & 47.4 & 6937_74 & QFAM & 1022 & & 1.48 & 0.00772 & & \\
\hline 2 & 48.4 & 61599_86 & QFAM & 1022 & & 1.48 & 0.00708 & & \\
\hline 2 & 48.4 & 83153_20 & QFAM & 1022 & & 1.48 & 0.00775 & & \\
\hline 3 & 20.3 & 68284_87 & GRAMMA & 979 & $-1.12(0.57)$ & 3.85 & 0.00979 & & \\
\hline 4 & 0 & 84080_123 & GRAMMA & 978 & $1.05(0.5)$ & 4.4 & 0.00575 & & \\
\hline 4 & 0 & 84080_123 & QFAM & 1021 & & 1.708 & 0.00232 & & \\
\hline 4 & 19.7 & 65405_244 & FASTA & 979 & $-2.07(0.73)$ & 7.95 & 0.00482 & & \\
\hline 4 & 19.7 & 65405_244 & GRAMMA & 979 & $-1.26(0.55)$ & 5.21 & 0.00268 & & \\
\hline 4 & 46.8 & 110358_408 & FASTA & 979 & $2.18(0.71)$ & 9.33 & 0.00226 & & c-type natriuretic peptide 1 precursor \\
\hline 4 & 46.8 & 110358_408 & GRAMMA & 979 & $1.3(0.53)$ & 5.96 & 0.00131 & * & c-type natriuretic peptide 1 precursor \\
\hline 4 & 46.8 & 110358_408 & QFAM & 1022 & & 2.058 & 0.00867 & & c-type natriuretic peptide 1 precursor \\
\hline 5 & 9.6 & 4797_109 & FASTA & 978 & $-1.57(0.55)$ & 8.06 & 0.00452 & & \\
\hline 5 & 9.6 & 4797_109 & GRAMMA & 978 & $-0.92(0.41)$ & 5.06 & 0.00307 & & \\
\hline 5 & 23.8 & 83820_94 & FASTA & 979 & $-2.05(0.72)$ & 8.14 & 0.00434 & & Brain specific kinase 146 \\
\hline 5 & 23.8 & 83820_94 & GRAMMA & 979 & $-0.97(0.48)$ & 4.12 & 0.00753 & & Brain specific kinase 146 \\
\hline 5 & 38.3 & 1886_343 & FASTA & 979 & $1.71(0.64)$ & 7.24 & 0.00712 & & loc100037090 protein \\
\hline 5 & 38.3 & 1886_343 & QFAM & 1022 & & 1.826 & 0.00577 & & loc100037090 protein \\
\hline 5 & 43.4 & 53540_630 & FASTA & 976 & $2.76(0.92)$ & 9.03 & 0.00265 & & protein phosphatase regulatory subunit 10 \\
\hline 5 & 43.4 & 53540_630 & GRAMMA & 976 & $1.28(0.59)$ & 4.71 & 0.00429 & & Protein phosphatase Regulatory subunit 10 \\
\hline 5 & 43.4 & 75322_75 & QFAM & 1022 & & -1.517 & 0.00759 & & \\
\hline 7 & 23.4 & 62374_157 & FASTA & 968 & $-3.59(1.04)$ & 11.99 & 0.00053 & * & \\
\hline 7 & 23.4 & 62374_157 & GRAMMA & 968 & $-2.26(0.8)$ & 7.99 & 0.0002 & $* *$ & \\
\hline 7 & 23.4 & 62374_157 & QFAM & 1016 & & -4.763 & 0.0041 & & \\
\hline 7 & 53.7 & 87974_385 & GRAMMA & 979 & $-0.95(0.48)$ & 3.96 & 0.00886 & & sec14-like 1 (cerevisiae) \\
\hline 8 & 23.3 & 136056_232 & GRAMMA & 979 & $-1.04(0.47)$ & 4.89 & 0.00362 & & \\
\hline 8 & 54.9 & 31265_40 & QFAM & 1022 & & 1.369 & 0.00338 & & cd22 antigen \\
\hline 10 & 29.6 & $82862 \_249$ & FASTA & 979 & $-1.99(0.73)$ & 7.32 & 0.00683 & & \\
\hline 10 & 29.6 & $82862 \_249$ & GRAMMA & 979 & $-1.11(0.53)$ & 4.39 & 0.00582 & & \\
\hline 12 & 31.1 & 57295_319 & QFAM & 1022 & & -1.117 & 0.00924 & & \\
\hline 12 & 37.8 & 52515_4545 & QFAM & 1022 & & 1.667 & 0.0088 & & titin a \\
\hline 12 & 37.8 & 63497_114 & QFAM & 1022 & & 1.667 & 0.009 & & Unnamed protein product [Tetraodon nigroviridis] \\
\hline 13 & 19.8 & 64435_287 & QFAM & 1022 & & 1.813 & 0.00376 & & Proline rich 5 \\
\hline 14 & 1.9 & 132996_241 & QFAM & 1021 & & 1.646 & 0.00159 & * & \\
\hline 14 & 12.5 & 112228_90 & FASTA & 979 & $2.09(0.65)$ & 10.32 & 0.00132 & * & \\
\hline 14 & 12.5 & 112228_90 & GRAMMA & 979 & $1.02(0.44)$ & 5.43 & 0.00216 & & \\
\hline 14 & 24.1 & $96692 \_167$ & FASTA & 979 & $1.53(0.59)$ & 6.79 & 0.00918 & & Novel protein prickle-like family \\
\hline 14 & 43.9 & 113696_50 & FASTA & 976 & $-3.39(1.15)$ & 8.75 & 0.0031 & & Perforin 1 (pore forming protein) \\
\hline 14 & 43.9 & 113696_50 & GRAMMA & 976 & $-2.22(0.91)$ & 5.92 & 0.00137 & * & Perforin 1 (pore forming protein) \\
\hline 15 & 1.1 & 13736_229 & GRAMMA & 979 & $-1(0.5)$ & 4.01 & 0.00844 & & \\
\hline 15 & 12.5 & 55466_266 & QFAM & 1022 & & 1.383 & 0.00078 & * & sept2 protein \\
\hline
\end{tabular}


Table 4 Suggestive and significant QTL for trait hours of survival after challenge with A. hydrophila detected using PLINK (QFAM) and GenAbel (FASTA and GRAMMA) analyses in 21 L. rohita families (Continued)

\begin{tabular}{|c|c|c|c|c|c|c|c|c|c|}
\hline 15 & 26.7 & 110434_333 & FASTA & 979 & $-1.93(0.75)$ & 6.72 & 0.00956 & & t cell antigen receptor alpha chain $\mathrm{c}$ region \\
\hline 15 & 26.7 & 110434_333 & GRAMMA & 979 & $-1.18(0.56)$ & 4.39 & 0.00584 & & t cell antigen receptor alpha chain $\mathrm{c}$ region \\
\hline 15 & 28.9 & 54100_91 & FASTA & 979 & $2.06(0.68)$ & 9.11 & 0.00255 & & cerebellin 1 precursor \\
\hline 15 & 28.9 & $60130 \_224$ & FASTA & 978 & $-1.95(0.66)$ & 8.7 & 0.00318 & & \\
\hline 15 & 28.9 & 60130_224 & GRAMMA & 978 & $-0.99(0.46)$ & 4.71 & 0.00429 & & \\
\hline 15 & 54.4 & 94824_55 & QFAM & 1022 & & -1.559 & 0.00057 & * & Adaptor-related protein complex mu 1 subunit \\
\hline 16 & 23.8 & 115737_104 & QFAM & 1020 & & -1.206 & 0.0094 & & $\begin{array}{c}\text { mucin-5b precursor (mucin } 5 \text { subtype tracheobronchial) } \\
\text { (high molecular weight salivary mucin mg1) } \\
\text { (sublingual gland mucin) }\end{array}$ \\
\hline 16 & 39.2 & 136477_76 & QFAM & 1022 & & 2.121 & 0.00687 & & sp2 transcription factor \\
\hline 18 & 8.4 & 60684_109 & GRAMMA & 978 & $-0.89(0.45)$ & 3.88 & 0.00958 & & \\
\hline 18 & 48.9 & 52766_1600 & FASTA & 979 & $-1.8(0.69)$ & 6.81 & 0.00909 & & $\begin{array}{c}\text { solute carrier family } 25 \\
\text { (mitochondrial carrier phosphate carrier) member } 25\end{array}$ \\
\hline 18 & 49.9 & 116665_768 & FASTA & 979 & $1.95(0.63)$ & 9.62 & 0.00193 & * & ptc7 protein phosphatase homolog (cerevisiae) \\
\hline 18 & 49.9 & 116665_768 & GRAMMA & 979 & $1.14(0.46)$ & 6.04 & 0.00122 & * & ptc7 protein phosphatase homolog (cerevisiae) \\
\hline 18 & 49.9 & 13427_160 & FASTA & 979 & $2.06(0.67)$ & 9.48 & 0.00208 & & \\
\hline 18 & 49.9 & 13427_160 & GRAMMA & 979 & $1.13(0.48)$ & 5.58 & 0.00188 & * & \\
\hline 19 & 23.8 & 111569_63 & FASTA & 979 & $2.49(0.77)$ & 10.44 & 0.00123 & * & tbt-binding protein \\
\hline 19 & 23.8 & 111569_63 & GRAMMA & 979 & $1.35(0.55)$ & 6.07 & 0.00119 & * & tbt-binding protein \\
\hline 20 & 0.8 & 54931_324 & GRAMMA & 979 & $1.16(0.59)$ & 3.86 & 0.0097 & & solute carrier family member 34 \\
\hline 20 & 3.3 & 134730_80 & FASTA & 970 & $-2.64(0.69)$ & 14.81 & 0.00012 & $* *$ & \\
\hline 20 & 3.3 & 134730_80 & GRAMMA & 970 & $-0.99(0.41)$ & 5.89 & 0.00141 & * & \\
\hline 20 & 3.3 & 134730_80 & QFAM & 1013 & & -2.504 & 0.0047 & & \\
\hline 20 & 7.9 & 88771_72 & FASTA & 954 & $-1.53(0.58)$ & 6.89 & 0.00866 & & \\
\hline 20 & 9.4 & 103839_124 & FASTA & 970 & $2.22(0.81)$ & 7.54 & 0.00603 & & \\
\hline 20 & 9.4 & 103839_124 & GRAMMA & 970 & $1.07(0.54)$ & 3.86 & 0.00974 & & \\
\hline 20 & 9.4 & 110140_1196 & FASTA & 979 & 1.6(0.6) & 7.06 & 0.00787 & & glycerol-3-phosphate dehydrogenase \\
\hline 20 & 9.4 & 110140_1196 & GRAMMA & 979 & $0.82(0.42)$ & 3.9 & 0.00938 & & glycerol-3-phosphate dehydrogenase \\
\hline 20 & 11.1 & 59816_21 & QFAM & 1022 & & -1.607 & 0.00152 & * & novel protein vertebrate stabilin 2 \\
\hline 20 & 20.3 & 134434_222 & FASTA & 978 & $-2.03(0.76)$ & 7.09 & 0.00776 & & \\
\hline 20 & 21.6 & 20086_69 & QFAM & 1022 & & 1.556 & 0.00996 & & vacuolar protein sorting $4 \mathrm{~b}$ \\
\hline 21 & 47.1 & 111636_59 & QFAM & 1022 & & 1.417 & 0.0044 & & kiaa1219 protein \\
\hline 21 & 51.1 & 54579_132 & FASTA & 979 & $1.63(0.55)$ & 8.68 & 0.00321 & & \\
\hline 21 & 51.1 & 54579_132 & GRAMMA & 979 & $1.04(0.43)$ & 5.95 & 0.00133 & * & \\
\hline 22 & 6 & 88524_52 & FASTA & 979 & $1.55(0.57)$ & 7.31 & 0.00687 & & \\
\hline 22 & 6 & 88524_52 & GRAMMA & 979 & $0.97(0.44)$ & 4.9 & 0.00357 & & \\
\hline 22 & 6.4 & 94914_114 & FASTA & 979 & $2.07(0.68)$ & 9.2 & 0.00242 & & \\
\hline 22 & 6.4 & 94914_114 & GRAMMA & 979 & $0.86(0.42)$ & 4.09 & 0.00775 & & \\
\hline 22 & 22.3 & 58881_141 & QFAM & 1022 & & -1.781 & 0.00352 & & tuberous sclerosis 1 \\
\hline 22 & 23.2 & 554_399 & FASTA & 979 & $-1.89(0.72)$ & 6.94 & 0.00841 & & dipeptidyl peptidase 7 \\
\hline 22 & 23.2 & 554_399 & GRAMMA & 979 & $-0.98(0.5)$ & 3.86 & 0.00974 & & dipeptidyl peptidase 7 \\
\hline 23 & 0 & 93296_256 & FASTA & 978 & $3.71(0.95)$ & 15.3 & 0.00009 & $* *$ & loc795887 protein \\
\hline 23 & 0 & 93296_256 & GRAMMA & 978 & $2.28(0.72)$ & 10.11 & 0.00003 & $* * *$ & loc795887 protein \\
\hline 23 & 0.9 & 110253_351 & FASTA & 979 & $2.35(0.77)$ & 9.27 & 0.00232 & & novel protein \\
\hline 23 & 0.9 & 110253_351 & GRAMMA & 979 & $1.27(0.55)$ & 5.36 & 0.00232 & & novel protein \\
\hline
\end{tabular}


Table 4 Suggestive and significant QTL for trait hours of survival after challenge with $A$. hydrophila detected using PLINK (QFAM) and GenAbel (FASTA and GRAMMA) analyses in 21 L. rohita families (Continued)

\begin{tabular}{|c|c|c|c|c|c|c|c|c|c|}
\hline 23 & 27.4 & $64731 \_210$ & QFAM & 1022 & & 1.41 & 0.00308 & & \\
\hline 24 & 55.9 & 67606_298 & FASTA & 979 & $-3.63(1.14)$ & 10.21 & 0.0014 & * & serine long chain base subunit 1 \\
\hline 24 & 55.9 & 67606_298 & GRAMMA & 979 & $-2.07(0.83)$ & 6.25 & 0.00101 & * & serine long chain base subunit 1 \\
\hline 25 & 46.1 & 54056_576 & FASTA & 979 & $1.7(0.65)$ & 6.87 & 0.00876 & & $\begin{array}{l}\text { n-ethylmaleimide sensitive fusion } \\
\text { protein attachment protein alpha }\end{array}$ \\
\hline
\end{tabular}

LG, linkage group; Pos, location on LG in centimorgans; N, number of progeny and parents analysed; Effect, allele substitution effect of the minor allele with standard error in parenthesis (FASTA and GRAMMAS); Stat, test statistic linear regression coefficient for QFAM, chi-square with one degree of freedom for FASTA and GRAMMA analyses; $P$, point-wise empirical $P$-value (QFAM) or permuted $P$-value with one degree of freedom corrected for inflation factor lambda (FASTA and GRAMMA); Sig, significance after Bonferroni correction $\left({ }^{*}, P<0.05 ;{ }^{* *}, P<0.01 ;{ }^{* * *}, P<0.001\right)$. GenelD, closest SNP homology from BLAST. Tests were considered suggestive when $P<0.01$ before Bonferroni correction.

has suggestive associations with both traits (Tables 4, 5 and 6). SNP 16321_60 with homology to the integrin alpha fg-gap repeat maps to $48 \mathrm{cM}$ on LG2, within $1 \mathrm{cM}$ of three SNPs with suggestive associations on hours of survival (Additional file 1, Table 4). SNP 134389_297 with homology to lymphocyte-specific protein tyrosine kinase maps approximately 2 cM from SNP 89585_200 (suggestive association with dead or alive) on LG3 (Additional file 1, Tables 5 and 6). SNP 98520_125 with homology to proteasome subunit beta type- 6 precursor maps to the same position, $9.6 \mathrm{cM}$ along LG5, as SNP 4797_109 (suggestive association with hours of survival) (Additional file 1, Tables 4 and 6). SNPs 111876_59 and 53025_556 with homology to the major histocompatibility locus I antigen (MHC I) and the c-type lectin receptor c map to $13 \mathrm{cM}$ and $18 \mathrm{cM}$ on LG5 respectively 3.4 and 5.8 cM from SNPs 4797_109 (suggestive association to hours of survival for the GRAMMA and FASTA tests, Additional file 1, Tables 4 and 6) and 83820_94 (suggestive association with both hours survival and dead or alive) respectively (Additional file 1, Tables 4, 5 and 6). A SNP with homology to e3 ubiquitin ligase (110314_603) occurs at the same location as SNP 62374_157 (significant association with hours of survival, FASTA $P<0.05$ and GRAMMA $P<0.01$ ), while another SNP with homology to immunity related gtpase e4 (134666_118) maps to the same position as SNP 87974_385 (sec14-like 1, suggestive associations with hours of survival and dead or alive) on LG7 (Additional file 1, Tables 4, 5 and 6). SNP 117051_67 with homology to ubiquitination factor e4b isoform 2 maps between two SNPs with suggestive associations, $1.7 \mathrm{cM}$ distant from SNP 82862_249 (hours of survival) and $1.8 \mathrm{~cm}$ distant from 54734_19 (dead or alive) on LG10 (Additional file 1, Tables 4 and 6). SNPs 17842_95, 53178_329 and 69593_98 all share homology with mucin 2 protein and map $3.9 \mathrm{cM}$ from SNP 55609_284 (suggestive association with dead or alive) on LG13 (Additional file 1, Tables 5 and 6). SNP 110434_333 with homology to the alpha chain $\mathrm{c}$ region of the $\mathrm{T}$ cell antigen receptor (suggestive associations with hours of survival) maps 2.2 cM from SNPs 54100_91 (suggestive associations with hours of survival) and 60130_224 (suggestive association with hours of survival and dead or alive) on LG15 (Additional file 1, Tables 4, 5 and 6). SNP 133571_269 with homology to MHC class II antigen beta chain maps 3.2 cM from 100422_182 (suggestive association with dead or alive) and SNP 52577_884 with homology to heat shock protein 70 maps $1.2 \mathrm{cM}$ from SNP 75070_130 (significant association with dead or alive, $P<0.05$ after Bonferroni correction for ASSOC, FASTA and GRAMMA) on LG18 (Additional file 1, Tables 5 and 6). SNP 2465_218 with homology to ubiquitin-conjugating enzyme e2 c maps $2.1 \mathrm{cM}$ from SNP 111636_59 (suggestive association with hours of survival) on LG21 (Additional file 1, Tables 4 and 6). SNP 83239_350 with homology to fish virus induced trim protein maps between two SNPs with suggestive associations, 0.3 cM from 554_399 and 0.6 cM distant from SNP 58881_141 (hour of survival) on LG22 (Additional file 1, Tables 4 and 6).

\section{Temporal gene expression changes with A. hydrophila infection}

Significant up-expression of the perforin gene was observed over the time course post-infection with A. hydrophila, particularly in rohu spleen and gill tissues (Figure 5). Perforin was highly up-expressed (20-fold) at $12 \mathrm{~h}$ postinfection. The expression level in spleen did not significantly differ from pre-infection levels over the rest of the time periods sampled. Up-expression in the liver began 1 hour post-infection infection ( 0.4 fold), was highest at $12 \mathrm{~h}$ post-challenge ( 1 fold), dropped to pre-infection levels at $24 \mathrm{~h}$ and again slight up-regulation was noticed from $48-72 \mathrm{~h}$ post-infection (0.27-0.3 fold). Expression levels in gill tissue fluctuated over the time course, with up-expression at $3 \mathrm{~h}$ (9 fold), reduced levels of expression at $6 \mathrm{~h}$ and $12 \mathrm{~h}$, increasing to the highest level at $24 \mathrm{~h}$ (11 fold), remaining high at $48 \mathrm{~h}$ (8 fold), decreasing to pre-infection levels at $72 \mathrm{~h}$ and increasing again at $7 \mathrm{~d}$ post-infection ( 7 fold).

\section{Discussion}

This study created an extensive new SNP linkage map resource for $L$. rohita that was used to scan the genome 
Table 5 Suggestive and significant QTL for trait dead or alive after challenge with $A$. hydrophila detected using PLINK (ASSOC) and GenAbel (FASTA and GRAMMA) analyses in 21 L. rohita families

\begin{tabular}{|c|c|c|c|c|c|c|c|c|c|}
\hline LG & Pos & SNP & Test & $\mathbf{N}$ & Effect & Stat & $P$-value & Sig & GenelD \\
\hline 1 & 37.3 & 55086_181 & ASSOC & 1022 & $0.102 / 0.146$ & 9.07 & 0.00685 & & Small heat shock \\
\hline 1 & 37.3 & 61478_69 & GRAMMA & 979 & $-0.06(0.03)$ & 6.54 & 0.0095 & & \\
\hline 1 & 44.1 & 116899_232 & GRAMMA & 979 & $0.07(0.03)$ & 6.69 & 0.00875 & & \\
\hline 1 & 44.1 & 116899_232 & ASSOC & 1022 & $0.447 / 0.393$ & 6.08 & 0.00625 & & \\
\hline 3 & 29 & 89585_200 & ASSOC & 1022 & $0.27 / 0.329$ & 8.62 & 0.00548 & & Cardiac ankyrin repeat protein \\
\hline 3 & 29 & 89585_200 & GRAMMA & 979 & $-0.07(0.02)$ & 6.9 & 0.00772 & & Cardiac ankyrin repeat protein \\
\hline 4 & 0.9 & 32879_80 & FASTA & 979 & $0.08(0.03)$ & 7.86 & 0.00505 & & \\
\hline 4 & 0.9 & 32879_80 & GRAMMA & 979 & $0.08(0.03)$ & 8.44 & 0.00321 & & \\
\hline 5 & 23.8 & 83820_94 & GRAMMA & 979 & $-0.07(0.03)$ & 6.71 & 0.00863 & & Brain specific kinase 146 \\
\hline 6 & 46.9 & 67578_280 & FASTA & 979 & $0.15(0.05)$ & 9.04 & 0.00264 & & Nicotinamide nucleotide transhydrogenase \\
\hline 6 & 46.9 & 67578_280 & GRAMMA & 979 & $0.15(0.05)$ & 9.71 & 0.00158 & * & Nicotinamide nucleotide transhydrogenase \\
\hline 6 & 46.9 & 67578_280 & ASSOC & 1022 & $0.097 / 0.063$ & 8.03 & 0.00397 & & Nicotinamide nucleotide transhydrogenase \\
\hline 6 & 46.9 & 87896_2052 & FASTA & 979 & $0.17(0.06)$ & 7.43 & 0.00643 & & Complement protein component c7-1 \\
\hline 6 & 46.9 & 87896_2052 & GRAMMA & 979 & $0.17(0.06)$ & 7.97 & 0.00419 & & Complement protein component c7-1 \\
\hline 7 & 53.7 & 87974_385 & FASTA & 979 & $-0.08(0.03)$ & 7.18 & 0.00738 & & sec14-like 1 (cerevisiae) \\
\hline 7 & 53.7 & 87974_385 & GRAMMA & 979 & $-0.08(0.03)$ & 7.71 & 0.00487 & & sec14-like 1 (cerevisiae) \\
\hline 7 & 53.7 & 87974_385 & ASSOC & 1022 & $0.246 / 0.3$ & 7.4 & 0.00568 & & sec14-like 1 (cerevisiae) \\
\hline 9 & 32.1 & 56368_90 & GRAMMA & 979 & $-0.07(0.02)$ & 6.98 & 0.00739 & & leucine-rich ppr-motif containing \\
\hline 10 & 26.1 & 54734_19 & FASTA & 979 & $0.08(0.03)$ & 6.75 & 0.00937 & & \\
\hline 10 & 26.1 & 54734_19 & GRAMMA & 979 & $0.08(0.03)$ & 7.25 & 0.00633 & & \\
\hline 10 & 34.8 & 133884_276 & GRAMMA & 979 & $-0.08(0.03)$ & 7.02 & 0.0072 & & \\
\hline 13 & 26.9 & 65946_186 & GRAMMA & 979 & $-0.1(0.04)$ & 6.48 & 0.00985 & & Cytoskeleton associated protein 5 \\
\hline 13 & 26.9 & 65946_186 & ASSOC & 1022 & $0.126 / 0.164$ & 6.03 & 0.0083 & & Cytoskeleton associated protein 5 \\
\hline 13 & 34.9 & 55609_284 & FASTA & 979 & $0.08(0.03)$ & 7 & 0.00816 & & Heavy subunit \\
\hline 13 & 34.9 & 55609_284 & GRAMMA & 979 & $0.08(0.03)$ & 7.51 & 0.00544 & & Heavy subunit \\
\hline 14 & 1.9 & 132996_241 & FASTA & 978 & $0.07(0.02)$ & 8.22 & 0.00415 & & \\
\hline 14 & 1.9 & 132996_241 & GRAMMA & 978 & $0.07(0.02)$ & 8.82 & 0.00259 & & \\
\hline 14 & 1.9 & 132996_241 & ASSOC & 1022 & $0.481 / 0.416$ & 8.83 & 0.00448 & & \\
\hline 14 & 12.5 & 112228_90 & FASTA & 979 & $0.08(0.03)$ & 9.4 & 0.00217 & & \\
\hline 14 & 12.5 & 112228_90 & GRAMMA & 979 & $0.08(0.03)$ & 10.1 & 0.00127 & * & \\
\hline 14 & 12.5 & 112228_90 & ASSOC & 1022 & $0.33 / 0.269$ & 8.99 & 0.00334 & & \\
\hline 14 & 24.1 & $96692 \_167$ & FASTA & 979 & $0.07(0.02)$ & 8.87 & 0.0029 & & Novel protein prickle-like family \\
\hline 14 & 24.1 & $96692 \_167$ & GRAMMA & 979 & $0.07(0.02)$ & 9.52 & 0.00175 & * & Novel protein prickle-like family \\
\hline 14 & 24.1 & $96692 \_167$ & ASSOC & 1022 & $0.446 / 0.515$ & 9.74 & 0.00588 & & Novel protein prickle-like family \\
\hline 14 & 47.1 & 4460_67 & ASSOC & 1022 & $0.372 / 0.46$ & 8.29 & 0.0003 & ** & \\
\hline 15 & 28.9 & 60130_224 & FASTA & 978 & $-0.08(0.03)$ & 8.64 & 0.00328 & & \\
\hline 15 & 28.9 & 60130_224 & GRAMMA & 978 & $-0.08(0.03)$ & 9.28 & 0.00201 & & \\
\hline 15 & 28.9 & 60130_224 & ASSOC & 1022 & $0.32 / 0.377$ & 7.21 & 0.005 & & \\
\hline 15 & 29.1 & 4834_117 & FASTA & 979 & $-0.07(0.03)$ & 6.92 & 0.00853 & & Novel protein \\
\hline 15 & 29.1 & 4834_117 & GRAMMA & 979 & $-0.07(0.03)$ & 7.43 & 0.00571 & & Novel protein \\
\hline 18 & 21.5 & 100422_182 & ASSOC & 1022 & $0.366 / 0.31$ & 7.16 & 0.00972 & & \\
\hline 18 & 35.5 & 75070_130 & FASTA & 979 & $0.1(0.03)$ & 10.37 & 0.00128 & * & \\
\hline 18 & 35.5 & 75070_130 & GRAMMA & 979 & $0.1(0.03)$ & 11.13 & 0.00072 & * & \\
\hline
\end{tabular}


Table 5 Suggestive and significant QTL for trait dead or alive after challenge with $A$. hydrophila detected using PLINK (ASSOC) and GenAbel (FASTA and GRAMMA) analyses in 21 L. rohita families (Continued)

\begin{tabular}{|c|c|c|c|c|c|c|c|c|c|}
\hline 18 & 35.5 & 75070_130 & ASSOC & 1022 & $0.241 / 0.183$ & 10.12 & 0.00095 & * & \\
\hline 19 & 8.5 & 63493_143 & GRAMMA & 979 & $-0.06(0.02)$ & 6.54 & 0.00948 & & \\
\hline 19 & 23.8 & 111569_63 & FASTA & 979 & $0.11(0.03)$ & 10.88 & 0.00097 & * & tbt-binding protein \\
\hline 19 & 23.8 & 111569_63 & GRAMMA & 979 & $0.11(0.03)$ & 11.68 & 0.00053 & * & tbt-binding protein \\
\hline 19 & 23.8 & 111569_63 & ASSOC & 1022 & $0.181 / 0.126$ & 11.86 & 0.00106 & * & tbt-binding protein \\
\hline 20 & 1.4 & 115437_120 & GRAMMA & 979 & $-0.1(0.04)$ & 6.46 & 0.00994 & & myosin heavy chain \\
\hline 20 & 3 & 55229_133 & ASSOC & 1022 & $0.342 / 0.284$ & 7.97 & 0.00459 & & denn madd domain containing $2 \mathrm{~d}$ \\
\hline 20 & 3 & 55229_133 & FASTA & 979 & $0.07(0.03)$ & 7.75 & 0.00537 & & denn madd domain containing $2 d$ \\
\hline 20 & 3 & 55229_133 & GRAMMA & 979 & $0.07(0.03)$ & 8.32 & 0.00344 & & denn madd domain containing $2 \mathrm{~d}$ \\
\hline 20 & 3.3 & 134730_80 & FASTA & 970 & $-0.07(0.02)$ & 8.75 & 0.00309 & & \\
\hline 20 & 3.3 & 134730_80 & GRAMMA & 970 & $-0.07(0.02)$ & 9.39 & 0.00189 & * & \\
\hline 20 & 3.3 & 134730_80 & ASSOC & 1022 & $0.332 / 0.398$ & 9.43 & 0.00392 & & \\
\hline 20 & 9.4 & 110140_1196 & FASTA & 979 & $0.06(0.02)$ & 6.71 & 0.00959 & & glycerol-3-phosphate dehydrogenase \\
\hline 20 & 9.4 & 110140_1196 & GRAMMA & 979 & $0.06(0.02)$ & 7.21 & 0.00649 & & glycerol-3-phosphate dehydrogenase \\
\hline 20 & 9.4 & 110140_1196 & ASSOC & 1022 & $0.44 / 0.378$ & 8 & 0.00638 & & glycerol-3-phosphate dehydrogenase \\
\hline 21 & 51.1 & 54579_132 & ASSOC & 1022 & $0.459 / 0.396$ & 8.05 & 0.00374 & & \\
\hline 23 & 0 & $93296 \_256$ & ASSOC & 1022 & $0.135 / 0.092$ & 9.15 & 0.00121 & * & loc795887 protein \\
\hline 23 & 0 & 93296_256 & FASTA & 978 & $0.11(0.04)$ & 6.69 & 0.00967 & & loc795887 protein \\
\hline 23 & 0 & 93296_256 & GRAMMA & 978 & $0.11(0.04)$ & 7.19 & 0.00656 & & loc795887 protein \\
\hline 24 & 49 & 110996_58 & ASSOC & 1022 & $0.204 / 0.26$ & 9.14 & 0.00508 & & \\
\hline 24 & 49 & 110996_58 & GRAMMA & 979 & $-0.07(0.03)$ & 6.9 & 0.00773 & & \\
\hline 24 & 51.5 & 110996_644 & ASSOC & 1022 & $0.086 / 0.124$ & 7.95 & 0.00843 & & \\
\hline 24 & 55.9 & 67606_298 & ASSOC & 1022 & $0.055 / 0.086$ & 7.86 & 0.00404 & & serine long chain base subunit 1 \\
\hline
\end{tabular}

LG, linkage group; Pos, location on LG in centimorgans; N, number of progeny and parents analysed; Effect, allele substitution effect of the minor allele with standard error in parenthesis (FASTA and GRAMMAS) or frequency of minor allele in case/control (ASSOC); Stat, chi-square with one degree of freedom for ASSOC, FASTA and GRAMMA analyses; $P$, point-wise empirical $P$-value (ASSOC) or permuted $P$-value with one degree of freedom corrected for inflation factor lambda (FASTA and GRAMMA); Sig, significance after Bonferroni correction $\left({ }^{*}, P<0.05 ;{ }^{* *}, P<0.01 ; * * *, P<0.001\right)$. GenelD, closest SNP homology from BLAST. Tests were considered suggestive when $P<0.01$ before Bonferroni correction.

for polymorphisms associated with A. hydrophila resistance. The SNPs occur in transcribed genes and were detected by looking for variation within and between populations of $L$. rohita that were differentially selected for either resistance or susceptibility to A. hydrophila [9]. This strategy was taken to maximise the possibility that some of the SNPs detected were the actual causative variants, or, that they would map closely to the actual causative gene variants affecting resistance to $A$. hydrophila.

\section{Linkage groups and genome coverage}

A dense genetic linkage map for $L$. rohita was created containing 3193 SNPs mapping to 25 linkage groups (Additional file 1) corresponding to the haploid number of chromosomes in L. rohita [12]. Other linkage mapping studies for carps have estimated map lengths of widely differing sizes. For example, common carp map sizes range from $1852 \mathrm{cM}$ to $5506 \mathrm{cM}$ (between 161 and 719 and markers were used in these studies generating between 42 and 64 linkage groups [13-16]). Many of these size estimates are likely to be inaccurate due to poor coverage. Genome lengths for the male and female maps in this study were 1407 and $1416 \mathrm{cM}$ respectively. The haploid genome of rohu has been estimated to consist of approximately 1950 million base pairs (based on the Feulgen microdensitometry method) [17]. Given the genome length estimate from our study we would therefore expect approximately 1.4 million bases per $\mathrm{cM}$ distance in the common carp genome. Pairwise recombination rates between informative linked markers were not significantly different for male compared to female meiosis.

More than $90 \%$ of BLAST search homology for the SNP annotation was with genes in the zebra fish (Danio rerio) genome [9]. The correspondence between the organisation of these two genomes was determined by comparing the linkage map positions of annotated $L$. rohita SNPs to the chromosomal position of the same genes in $D$. rerio. Some chromosomal rearrangement since these species diverged from a common ancestor some 10-250 million years ago [18] was observed (Additional file 3). A few 

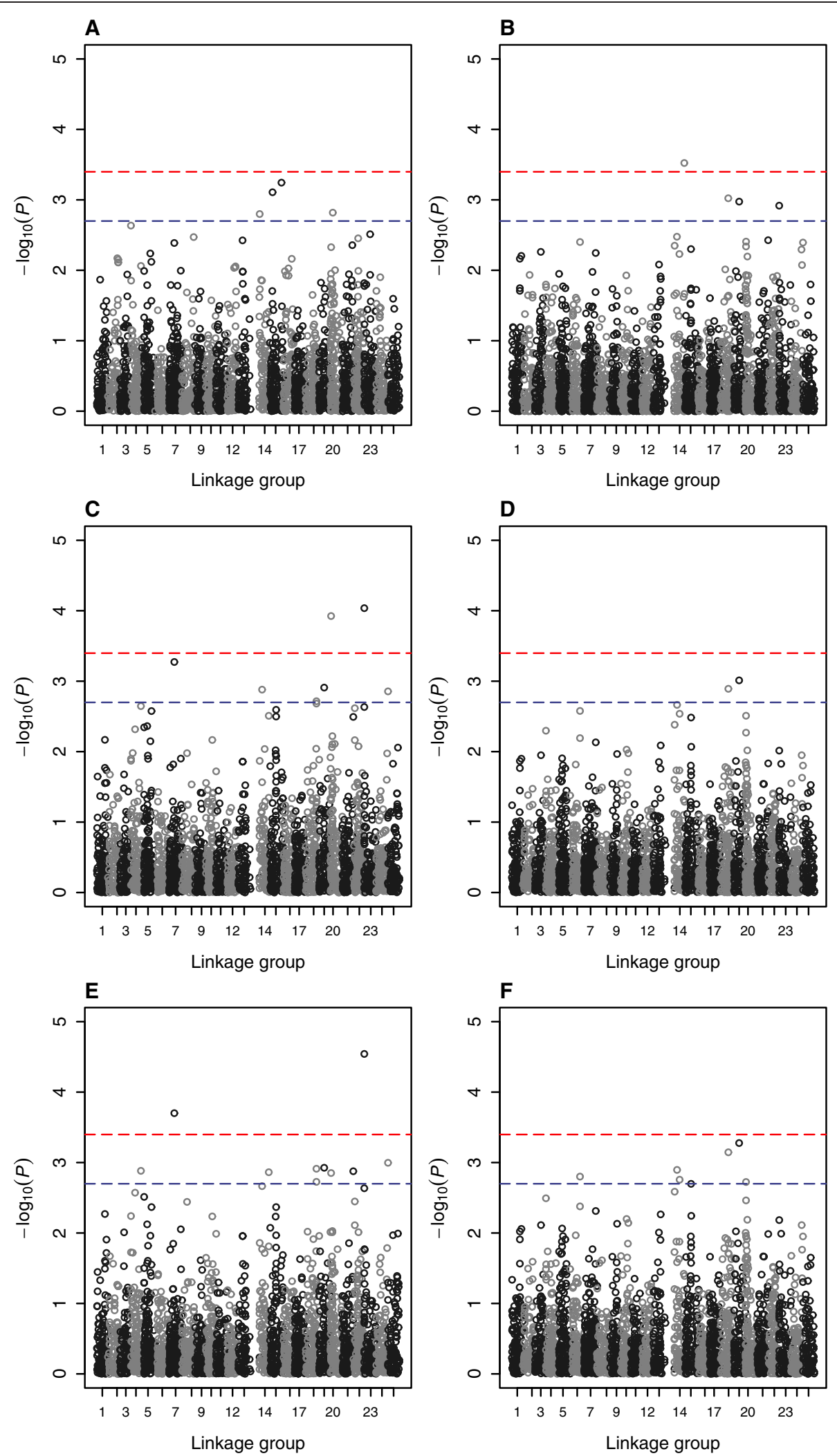

Figure 1 (See legend on next page.) 
(See figure on previous page.)

Figure 1 Manhattan plots showing corrected $P$-values with 1 degrees of freedom after permutation testing for SNPs across the 25 linkage groups for traits hours of survival (plots A, C and E) and dead or alive (plots B, D and F) for tests QFAM (plot A), ASSOC (plot B), FASTA (plots C and D) and GRAMMA (plots $\mathbf{E}$ and F). Linkage group positions are shown in centimorgons (cM) on the horizontal axis. Upper and lower dotted lines mark significance thresholds after Bonferroni correction of $P<0.01$ and $P<0.05$ respectively.

scattered genes mapped to different $D$. rerio chromosomes than neighbouring genes on the $L$. rohita linkage map. This may be due to actual chromosome rearrangements (eg. caused by transposable elements) or due to errors of identification caused by BLAST similarity with closely related gene sequences on other chromosomes. Most of these differences occur towards the end of the L. rohita linkage groups which is also where rearrangements of large blocks of genes within linkage groups/chromosomes were detected (eg. towards the end of linkage group 18 in L. rohita). The gene sequences themselves shared high similarity (average similarity $87 \pm 0.3 \% \mathrm{SE}$ ).

\section{Candidate genes mapping to QTL regions}

A number of SNPs in contigs with homology to genes of known immune function were found to either be the SNPs, or map closely (within $5 \mathrm{cM}$ distance) to SNPs, with suggestive $(P<0.01$ before Bonferroni correction) or significant $(P<0.05$ after Bonferroni correction) associations with hours of survival and/or dead or alive traits after challenge with $A$. hydrophila (Tables 4, 5 and 6).

The ubiquitin-protein ligases or E3 enzymes (e3 ubiquitin ligase 1110314_603 on LG7, ubiquitination factor e4b isoform 2 117051_67 on LG10 and ubiquitin-conjugating enzyme e2 c 2465_218 on LG21, Table 6) are a diverse group of enzymes that, as part of an enzyme cascade, attach ubiquitin to a lysine on the target protein resulting in poly- or mono-ubiquination which targets specific protein substrates for degradation by the proteasome (proteolysis) [19]. More than 500 distinct E3 enzymes have been found in mammals. Silencing of ubiquitin ligase associated proteins has been shown to affect disease resistance in plants [20]. A SNP coding for e3 ubiquitin ligase occurs at the same map position around 23.4 cM on LG7 as SNP 62374_157 which is significantly associated with hours of survival (FASTA $P<0.05$ and GRAMMA $P<0.01$ after Bonferroni correction Additional file 1, Table 4).

The proteasome is a large complex which catalyses the degradation of ubiquitinated proteins, a process requiring ATP to unfold and translocate the substrate into the core of the proteasome for proteolysis [21]. The architecture of the proteasome ensures that only those molecules which are targeted for degradation are affected and the proteolytic enzymes at the core of the proteasome cleave peptide bonds with broad specificity. With degradation of intracellular proteins by the proteasome, some of the by-products are transported to the endoplasmic reticulum where they bind to major histocompatibility class I molecules and result in antibody production [22]. Variation in the proteasome subunit genes (eg. variation in the proteasome subunit beta type- 6 precursor) which affects the structure and function of the proteasome could therefore have downstream effects on cellular immunity.

Lymphocyte-specific protein tyrosine kinase (SNP 134389_297 on LG 3, Table 6) is highly expressed in the thymus, initiates tyrosine phosphorylation cascade in T-cells and plays a crucial role in T-cell maturation, signalling and hence immunity [23-25]. The basic mechanisms that regulate expression of this gene have been shown to be highly conserved between teleost fish and mammals [26].

The major histocompatibility class I antigen (MHC I, 111876_59 on LG5, Table 6) alerts the immune system to the presence of foreign material inside a cell. MHC I presenting proteins (HLS's) occur on the cell surface. The MHC II interacting molecule CD4 communicates with T-cell receptors, and it is MHC II (133571_269 on LG 18, Table 6) that is known to mainly fight bacterial pathogens [27], although MHC I has evolved MHC II type functionality in some fish species such as Atlantic cod Gadus morhua [28]. Three MHC class I alleles have been found to be associated with improved resistance and four MHC class II alleles were found to be associated with increased susceptibility of Atlantic salmon to Aeromonas salmonicida infection [29]. Fixed allele frequency differences were detected for several MHC I SNPs, including SNP 111876_59 which mapped 3.4 cM from the QTL detected on LG5, between samples from lines of rohu that were selected for resistance or susceptibility to A. hydrophila [9]. More than 5-fold up- or down-regulation of MHC I transcripts was also detected in the resistant line fish using mRNA-seq and differential expression was confirmed for one transcript (contig 88601) in the skin, gill and intestine using RT qPCR [9].

The highly variable alpha chain of the $\mathrm{T}$ cell receptor (110434_333 on LG15, Table 6) occurs on the surface of $\mathrm{T}$ lymphocytes, and along with the beta chain, recognises antigens bound to MHC molecules. Two c alpha chain molecules have been detected in common carp (possibly as a result of tetraploidisation) [30]. A. hydrophila has been found to significantly increase the expression of beta chain $\mathrm{T}$ cell antigen receptors in Nile tilapia peripheral blood leukocytes grown in culture [31]. Activation of invariant natural killer $\mathrm{T}$ cells, with an invariant $\mathrm{T}$-cell antigen receptor alpha chain, have been proposed as attractive targets for developing new vaccines for infectious diseases because of their ability to recognise 

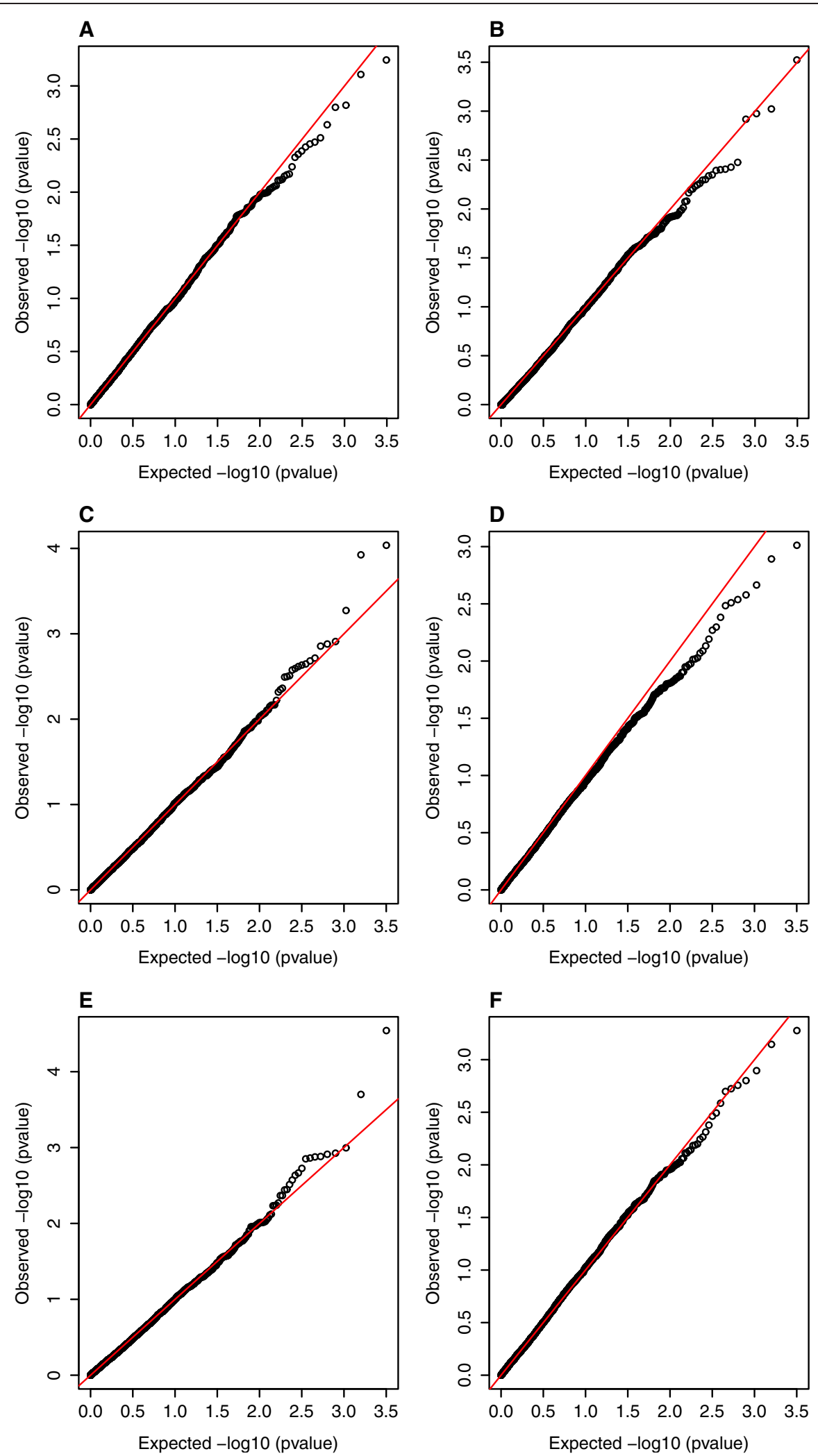

Figure $2 \mathrm{QQ}$ plots showing observed and expected corrected $P$-values with 1 degrees of freedom after permutation for SNPs tested across the 25 linkage groups for traits hours of survival (plots $A, C$ and $E$ ) and dead or alive (plots $B, D$ and F) for tests QFAM (plot A), ASSOC (plot B), FASTA (plots C and D) and GRAMMA (plots E and F). 


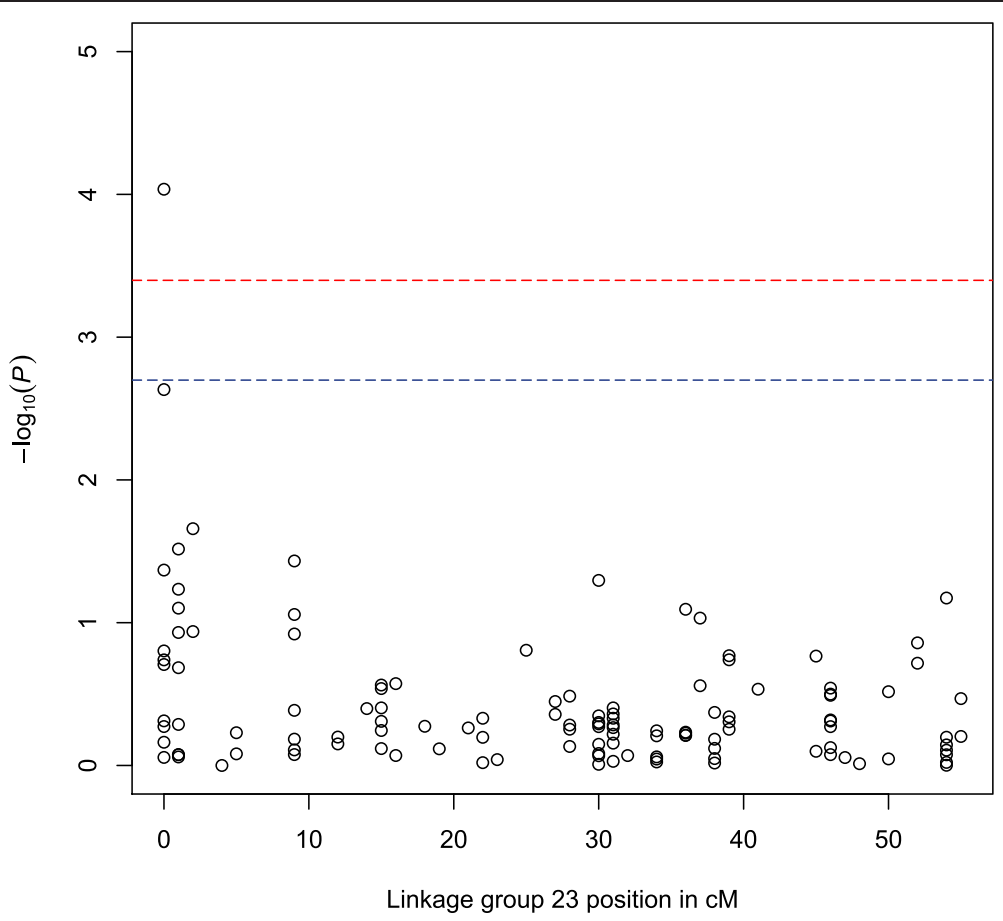

Figure 3 Manhattan plot showing corrected $P$-values with 1 degrees of freedom after permutation testing for SNPs across linkage group $\mathbf{2 3}$ for the trait hours of survival for test FASTA. Linkage group positions are shown in centimorgons (cM) on the horizontal axis. Upper and lower dotted lines mark significance thresholds after Bonferroni correction of $P<0.01$ and $P<0.05$ respectively.

glycolipid antigens from pathogenic bacteria including Streptococcus pneumonia [32].

Heat shock $70 \mathrm{kDa}$ (HSP70 or mortalin, 52577_884 on LG18, Table 6) binds to antigen presenting cells via toll-like receptors and leads to the secretion of pro-inflammatory cytokines and broad immunostimulation [33]. HSP70 acts as an intracellular chaperone, which stabilises proteins, giving them a possible role in general stress tolerance. This protein plays a role in cell proliferation, stress response and maintenance of the mitochondria. Seven contigs with homology to HSP70 were up-regulated more than 3fold (median 4.89) in resistant compared to susceptible line rohu [9]. Heat shock protein 105/110 (53470_163 on LG1, Table 6) is a member of the HSP70 family of molecular chaperones which functionally relates to heat shock cognate protein 70 (HSC70) and HSP90, and is known to prevent the aggregation of denatured proteins in cells under severe stress [34]. HSP60 (132709_550 on LG14, Table 6), like HSP70, is believed to play an important role in the control of the immune response [35].

A number of genes with putative functions affecting mucous secretions (mucin-5b precursor 115737_104 on LG 16, mucin 2 17842_95, mucin 2 53178_329 and mucin subtype tracheobronchial 69593_98 on LG13, Table 6) were associated with QTL of significant or suggestive association with the two traits. Two rohu contigs with homology to the mucin-5b precursor gene [detected by 9] were on average 3.8 times more highly expressed in resistant line than susceptible line fish (interquartile range 1.28 , Figure 4). Five contigs with homology to mucin 2 [detected by 9] were on average 2.29 more highly expressed in resistant line than susceptible line rohu (interquartile range 0.362). High molecular weight glycoprotein polymers called mucins are found on the outer body surfaces and intestine of fish. These glycoproteins form a highly viscous gel that protects the epithelium from microbial and other disturbances. Common carp increase the amount and total glycosylation of high molecular weight glycoproteins in the skin in response to increased bacterial loads [36,37]. Twenty-six contigs with homology to zona pellucida glycoprotein have been found to show two- to sevenfold higher expression (median 4.13, interquartile range 2.45) in resistant compared to susceptible line rohu [9]. Choriogenin is another high molecular weight glycoprotein and was found to be 3.5 times more highly expressed in resistant compared to susceptible line rohu [9]. Higher expression of these glycoprotein genes could result in the secretion of greater quantities of glycoproteins, including mucin, on the skin and gut surface leading to greater protection and readiness against bacterial disease.

Serum lectins (c-type lectin receptor c 53025_556 on LG5, Table 6) are found in the mucus and have been shown to agglutinate with and alter the viability and 
Table 6 SNPs with homology to genes of putative immune function mapping near to QTL regions

\begin{tabular}{|c|c|c|c|c|c|c|c|c|}
\hline \multicolumn{2}{|r|}{ QTL } & \multicolumn{7}{|c|}{ Closely mapping SNPs of putative immune function } \\
\hline LG & cM & cM & SNP & GenelD & Length & Hits & E-value & Similarity \\
\hline \multirow[t]{3}{*}{1} & 37.3 and 44.1 & 32.1 & 53470_163 & Heat shock protein $105 \mathrm{kd}$ & 615 & 10 & 9.33E-87 & $63.30 \%$ \\
\hline & & 32.9 & 52852_1499 & Complement c4 & 1991 & 10 & 0 & $62.60 \%$ \\
\hline & & 37.3 & 55086_181 & Small heat shock protein & 857 & 10 & $6.64 \mathrm{E}-44$ & $81.40 \%$ \\
\hline 2 & $43.9,47.4$ and 48.4 & 48 & 16321_60 & Integrin alpha fg-gap repeat & 127 & 3 & $5.33 \mathrm{E}-12$ & $84.33 \%$ \\
\hline 3 & 20.3 and 29 & 27.4 & 134389_297 & $\begin{array}{l}\text { lymphocyte-specific protein } \\
\text { tyrosine kinase }\end{array}$ & 435 & 10 & $2.66 \mathrm{E}-64$ & $89.90 \%$ \\
\hline 4 & $0,0.9,19.7$ and $46.8^{*}$ & - & - & - & - & - & - & - \\
\hline \multirow[t]{3}{*}{5} & $9.6,23.8,38.3$ and 43.4 & 9.6 & 98520_125 & $\begin{array}{l}\text { proteasome subunit beta } \\
\text { type-6 precursor }\end{array}$ & 168 & 10 & $9.08 \mathrm{E}-20$ & $93.90 \%$ \\
\hline & & 13 & 111876_59 & major histocompatibility locus I antigen & 250 & 10 & $9.21 \mathrm{E}-33$ & $89.10 \%$ \\
\hline & & 18 & 53025_556 & c-type lectin receptor $\mathrm{c}$ & 1141 & 10 & 7.40E-106 & $62.40 \%$ \\
\hline 6 & $46.9^{*}$ & 46.9 & 87896_2052 & complement protein component c7-1 & 2667 & 10 & 0 & $71.50 \%$ \\
\hline \multirow[t]{2}{*}{7} & $23.4^{* *}$ and 53.7 & 22.6 & 110314_603 & e3 ubiquitin ligase & 888 & 10 & 2.19E-138 & $66.90 \%$ \\
\hline & & 54.4 & 134666_118 & immunity related gtpase e4 & 203 & 10 & $2.16 \mathrm{E}-21$ & $66.70 \%$ \\
\hline 8 & 23.3 and 54.9 & 54.9 & 31265_40 & CD22 antigen & 128 & 1 & $1.66 \mathrm{E}-05$ & $71.00 \%$ \\
\hline 9 & 32.1 & - & - & - & - & - & - & - \\
\hline 10 & $26.1,29.6$ and 34.8 & 27.9 & 117051_67 & ubiquitination factor e4b isoform 2 & 116 & 10 & $9.21 \mathrm{E}-12$ & $97.00 \%$ \\
\hline 12 & 31.1 and 37.8 & - & - & - & - & - & - & - \\
\hline \multirow[t]{3}{*}{13} & $19.8,26.9$ and 34.9 & 31 & 17842_95 & mucin 2 protein & 172 & 10 & $7.15 \mathrm{E}-17$ & $80.70 \%$ \\
\hline & & 31 & 53178_329 & mucin 2 protein & 2002 & 10 & 0 & $59.10 \%$ \\
\hline & & 31 & 69593_98 & mucin subtype tracheobronchial & 307 & 10 & $2.79 \mathrm{E}-45$ & $79.30 \%$ \\
\hline \multirow[t]{2}{*}{14} & $1.9^{*}, 12.5^{*}, 24.1^{*}, 43.9^{*}$ and $47.1^{* *}$ & $43.9^{*}$ & 113696_50 & perforin 1 & 233 & 10 & $1.23 \mathrm{E}-24$ & $67.10 \%$ \\
\hline & & 47.1 & 132709_550 & $\begin{array}{c}\text { chaperonin (HSP60) containing } \\
\text { subunit } 2\end{array}$ & 922 & 10 & $6.24 \mathrm{E}-123$ & $95.60 \%$ \\
\hline 15 & $1.1,12.5^{*}, 26.7,28.9,29.1$ and $54.4^{*}$ & 26.7 & 110434_333 & $\begin{array}{l}\text { t-cell antigen receptor alpha } \\
\text { chain c region }\end{array}$ & 381 & 10 & $6.69 \mathrm{E}-31$ & $74.00 \%$ \\
\hline 16 & 23.8 and 39.2 & 23.8 & 115737_104 & mucin-5b precursor & 347 & 3 & $9.86 \mathrm{E}-06$ & $47.00 \%$ \\
\hline \multirow[t]{2}{*}{18} & $8.4,21.5,35.5^{*}, 48.9$ and $49.9^{*}$ & 18.2 & 133571_269 & MHC class II antigen beta chain & 391 & 10 & $2.05 E-32$ & $76.50 \%$ \\
\hline & & 36.7 & 52577_884 & heat shock protein 70 & 2527 & 10 & 0 & $92.60 \%$ \\
\hline 19 & $23.8^{*}$ & $23.8^{*}$ & 111569_63 & tributyltin (tbt)-binding protein & 393 & 10 & $1.91 \mathrm{E}-46$ & $50.50 \%$ \\
\hline 20 & $0.8,1.4,3,3.3^{*}, 7.9,9.4,11.1^{*}, 20.3$ and 21.6 & - & - & - & - & - & - & - \\
\hline 21 & 47.1 and $51.1^{*}$ & 45.2 & 2465_218 & ubiquitin-conjugating enzyme e2 c & 279 & 10 & $1.75 E-31$ & $95.30 \%$ \\
\hline 22 & $6,6.4,22.3$ and 23.2 & 22.9 & 83239_350 & fish virus induced trim protein & 447 & 10 & $3.79 \mathrm{E}-66$ & $65.10 \%$ \\
\hline \multirow[t]{2}{*}{23} & $0^{* * *}, 0.9$ and 27.4 & 0.7 & 55156_84 & dermatin sulphate epimerase & 378 & 10 & 4.94E-66 & $80.30 \%$ \\
\hline & & 23.2 & 554_399 & dipeptidyl-peptidase 7 & 502 & 10 & $1.19 \mathrm{E}-67$ & $76.00 \%$ \\
\hline 24 & $49,51.5$ and $55.9^{*}$ & - & - & - & - & - & - & - \\
\hline 25 & 46.1 & - & - & - & - & - & - & - \\
\hline
\end{tabular}

pathogenicity of Gram-negative bacteria including $A$. hydrophila [38-41]. Seven-fold higher expression of the serum lectin isoform 1 precursor gene was detected in resistant line than susceptible line rohu, and alternative isoforms of galactoside-binding soluble lectin 9 in resistant and susceptible line rohu were detected by [9] Along with a higher production of mucin, higher production of lectins found in the mucus of the skin and gut could lead to a greater preparedness to combat and resist infection by bacterial pathogens. Cluster of differentiation 


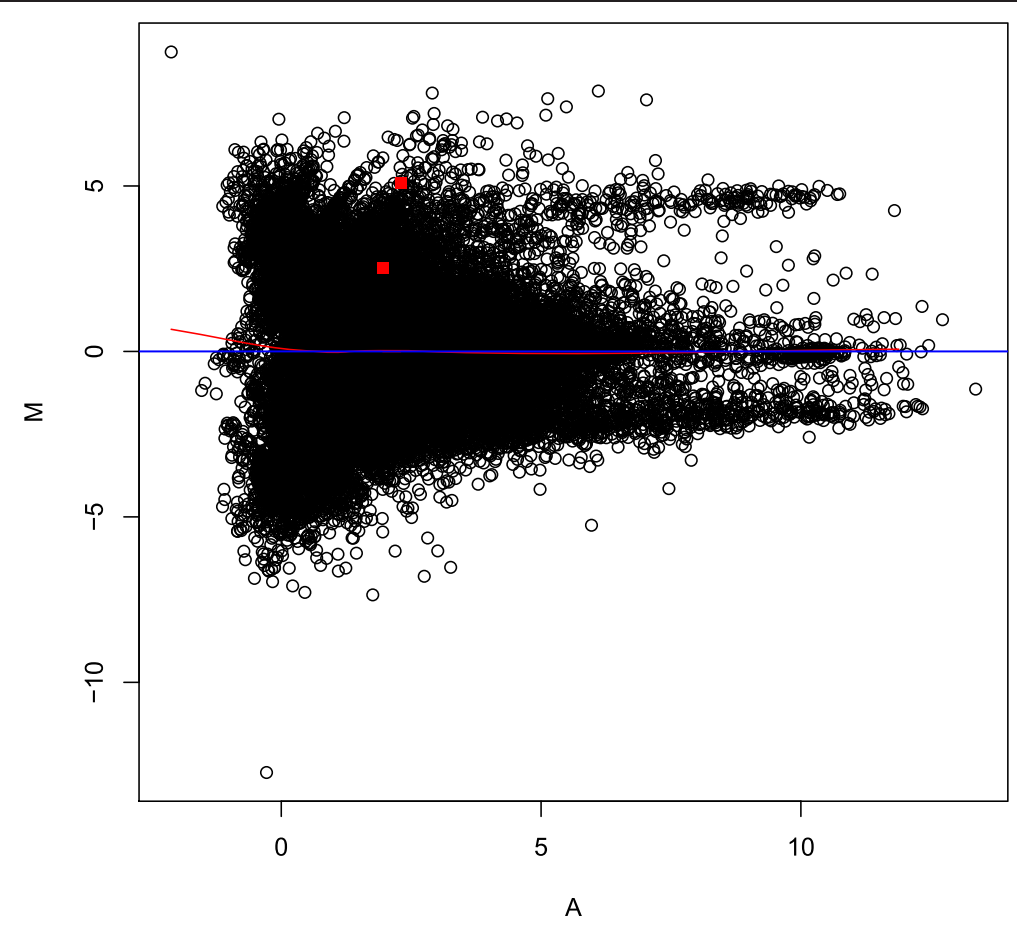

Figure 4 Bland-Altman MA plots of quantile normalised $\log _{2}$ transformed coverage data. Overall plot for 137,629 contigs (open circles) is overlayed with two highlighted contigs (shaded squares) showing homology to the mucin-5b precursor gene.

22 (CD22 antigen 31265_40 on LG8, Tables 4 and 5) is a lectin that is found on the surface of mature $B$ cells and prevents over activation of the immune system [42]. CD22 is a negative regulator of antigen receptor signaling in $\mathrm{B}$ cells. In mice CD22 is down-regulated on wild-type B-1 cells in response to LPS [43].

Tributyltin binding protein (111569_63 on LG 19, $P<0.05$ after Bonferroni correction for FASTA and GRAMMA tests for hours of survival and FASTA, GRAMMA and ASSOC tests for dead or alive, Tables 4 and 5) is a glycoprotein (possible lipocalin) that is believed to be involved in the transportation, detoxification and excretion of xenobiotic compounds such as tributyltin in the blood of Japanese flounder [44]. Tributyltin-binding protein is excreted from the body of Japanese flounder via the skin mucus. Tributyltin-binding protein is upexpressed more than four fold in the spleen of turbot 3 days after challenge with Aeromonas salmonicida [45].

Complement protein component c7 (87896_2052 on LG6, Table 5) plays an important role in the membrane attack system of the innate and adaptive immune response by serving as a membrane anchor, facilitating the formation of pores in the plasma membrane of target cells [46]. In a condition known as complement component 7 deficiency, human patients are more susceptible to recurrent infections, particularly to bacterial diseases such as caused by meningococcal infection [47].
Other genes with putative immune function with SNPs of interest included pore forming protein (perforin 1 113696_50 on LG 14, $P<0.05$ after Bonferroni correction for the GRAMMA test of hours of survival, Table 4) which is a key molecule involved in T-cell and natural killer-cell-mediated cytolysis, inserting itself into the target membrane forming a pore which allows cytolytic proteins to enter the cell and trigger it to self-destruct [48], dipeptidylpeptidase 7 (554_399 on LG22, Table 4) which suppresses apoptosis of resting lymphocytes [49] and immunity related gtpase e4 (134666_118 on LG 7, Table 6) which is one of a family of proteins that are activated as part of an early immune response (induced by interferon) and that localises to and disrupts the phagocytic vacuole during infection. Large temporal changes in perforin gene expression post-infection were detected by quantitative real-time PCR in spleen (up to +20 fold at $12 \mathrm{~h}$ post-infection, Figure $5 \mathrm{a})$ and gill tissue $(9,11,8$ and 7 fold at $3 \mathrm{~h}, 24 \mathrm{~h}, 48 \mathrm{~h}$ and 7 days post-infection, respectively, Figure $5 \mathrm{c}$ ). Along with linkage and genome-wide association evidence for a QTL mapping to the perforin gene region on LG14 (Tables 3, 4 and 5), these patterns suggest that differential expression of the perforin gene itself could play an important role in the immune defense of L. rohita against $A$. hydrophila infection, and that polymorphisms affecting the expression of this gene during the time course of infection could influence disease resistance. 

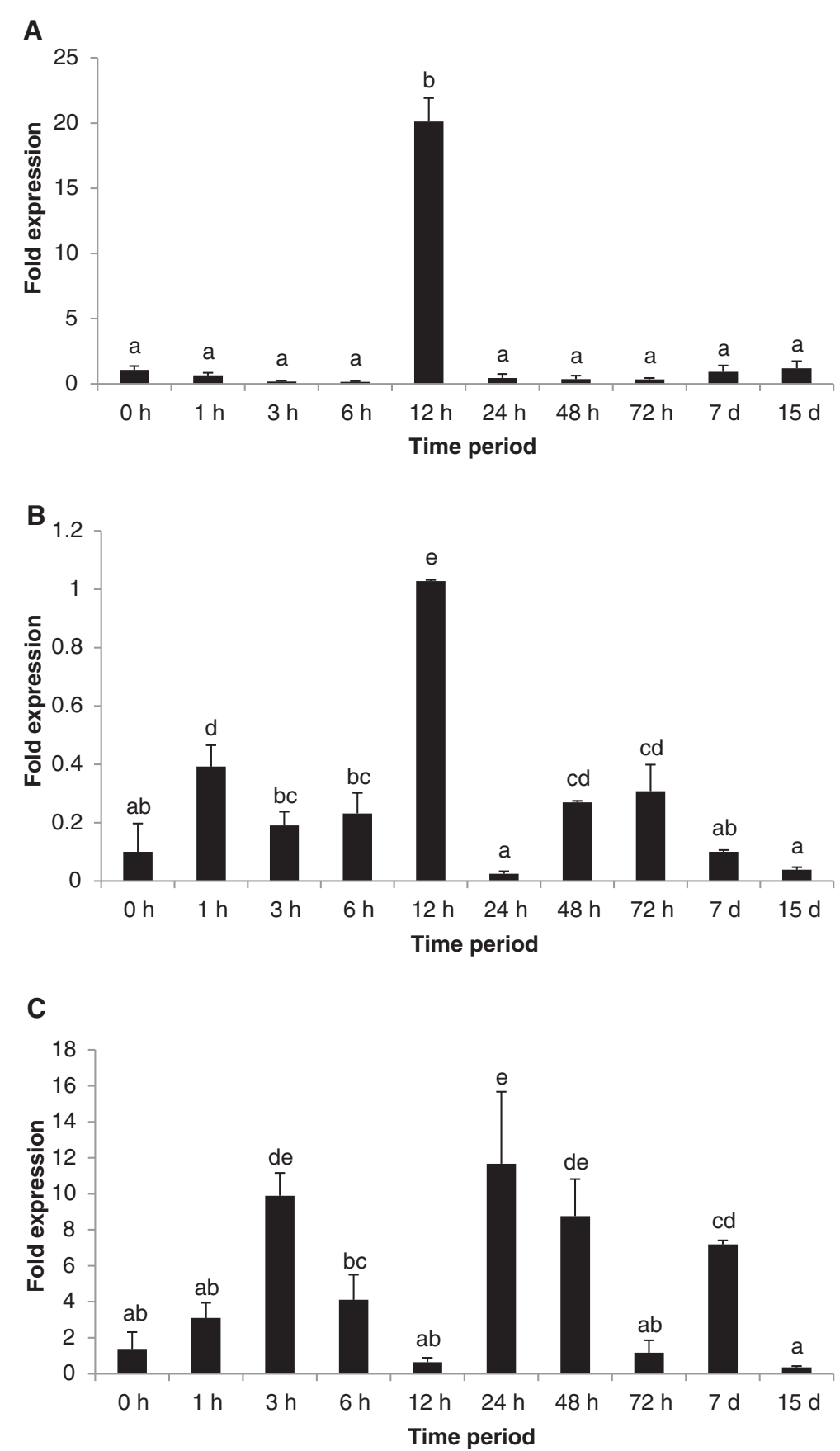

Figure 5 Temporal expression analysis of the perforin gene in spleen (A), liver (B) and gill (C) tissues of L. rohita hours (h) and days (d) after infection with $A$. hydrophila. Fold expression was calculated as $2^{-\Delta \Lambda \subset q}$. The control group (0 hour post-challenge) was used for calibration. Bars bearing different superscript are significantly different $(P<0.05)$.

\section{Comparison of traits and tests}

In all cases except one, the position of QTL mapped using half-sib regression analysis co-located within $10 \mathrm{cM}$ of a nominally significant SNP in the GWAS analysis for the two traits. In two cases on LG15 at 29 cM and LG23 at $0 \mathrm{cM}$, the QTL peak from the linkage analysis (Table 3) co-located to the same position as significant SNPs in the
GWAS analysis for the hours of survival trait (Table 4). There was good correspondence between the results for the ASSOC, FASTA and QFAM GWAS test results (most suggestive/significant results were detected by $>1$ GWAS test). As the challenge tests were performed for the different families over different total time frames it was not valid to compare hours of survival between families using 
the "total" option in qfam. The concordance between the findings for the hours of survival and dead or alive trait analyses was fairly high. Overall, many of the same regions (on linkage groups 1, 4, 5, 7, 10, 14, 15, 19, 20, 21, 23 and 24) contained SNPs with suggestive or significant associations for both the hours of survival and dead or alive traits (Tables 4 and 5), heritability estimates for both traits were similar (0.05 and 0.07 respectively) and the genetic correlation between the two traits was high and positive (0.79), indicating that the same underlying genetic mechanisms may be affecting these traits.

As the heritability of hours of survival and dead or alive post-challenge with $A$. hydrophila is low (similar levels of heritability for $A$. hydrophila resistance have been found for common carp, 0.04) [50] this is likely to be a polygenic trait influenced by the small additive effects of many genes and by the environment. Polymorphisms affecting the regulation of expression or amino acid structure of the proteins expressed by the immune genes highlighted in this study could be the type of causative mutations contributing to overall A. hydrophila resistance in $L$. rohita. It is not possible to identify the causative mutations from the results of this current study, but the genes and linkage group regions highlighted here provide clues that will direct the focus of future investigations, and provide potentially useful loci for marker assisted selection to improve $A$. hydrophila resistance in this and related species.

\section{Conclusions}

In summary, an important resource has been developed and used to screen the L. rohita genome for quantitative trait loci associated with disease resistance. mRNA-seq was used by a previous study to identify SNPs in transcribed genes using samples from susceptible and resistant line rohu [9]. In the current study 3194 of these SNPs were mapped to 25 linkage groups (average interval distance of $1.3 \mathrm{cM}$ ) and used to detect quantitative trait loci associated with resistance to $A$. hydrophila. Associations with resistance to $A$. hydrophila of significance after Bonferroni correction mapped to linkage groups 4, 6, 7, $14,15,18,19,20,21,23$ and 24. Genes of immune function mapping closely to these QTL include heat shock protein 70 , heat shock protein 60 , heat shock protein 105, "small heat shock protein", mucin $5 \mathrm{~b}$ precursor, mucin 2, lectin receptor, CD22, tributyltin-binding protein, major histocompatibility loci I, major histocompatibility II, complement protein component c7-1, perforin, ubiquitin ligase, ubiquitination factor e4b isoform 2 , ubiquitin-conjugation enzyme e2 c, proteasome subunit, T-cell antigen receptor and lymphocyte specific protein tyrosine kinase. The SNPs detected in association with disease resistance traits could be useful markers for improving the disease resistance of farmed rohu populations with selective breeding. They may also prove to be useful markers for Aeromoniasis resistance in closely related species such as common carp. Further work should be undertaken to confirm the associations detected in rohu carp and to determine whether the results are transferrable to other carp species. Genes of putative immune function mapping closely to these QTL provide leads for future work aiming to improve our understanding of the causative genetic variants affecting disease resistance. Knock-out gene studies on rohu, or on closely related model species such as zebra fish, could be used to determine whether the regulation of expression of these genes affects disease resistance, or whether other functional differences are involved. Elucidating the precise immune function of these genes will be a challenge, but such knowledge could hold large benefits for the world's aquaculture production, which relies so heavily on carp species affected by this disease.

\section{Methods}

\section{A. hydrophila challenge experiment}

The rohu fingerlings used for the study were generated under a selective breeding program initiated at the Central Institute of Freshwater Aquaculture (CIFA) India in 1992 under an Indo-Norwegian collaboration between CIFA and Institute of Aquaculture Research (AKVAFORSK), Norway. The original founders of the breeding program were sourced before 1992 as fry or fingerlings from five rivers in India (the Ganga, the Gomati, the Yamuna, the Brahmaputra and the Sutlej) [51,52]. All fingerlings for this study were derived from the 2008 year class of the breeding program which had been selected over seven generations for increased growth rate. Twentyone full-sibling families were represented. Different sire and dam individuals were pair mated to produce each family. However, four of the parents were themselves derived from two full-sib dam families. The parents were from the sixth generation of the selective breeding program (2005 \& 2006 year classes). The families were challenge tested during April-May, 2009. Five hundred juvenile rohu fingerlings from each family were collected from the nursery ponds, transferred to cement tanks $\left(10 \times 5 \mathrm{~m}^{2}\right)$ and left for two weeks acclimatization. Fish were fed a standard commercial pellet diet (3\% of body weight in two doses daily). One tenth of the water in the tank was exchanged daily for the removal of faecal material and unused feed. An overnight culture of $A$. hydrophila was grown in tryptone soya broth at $30^{\circ} \mathrm{C}$ for $20 \mathrm{~h}$. Fish were challenged with the same pathogenic strain of $A$. hydrophila intraperitoneally at an LD50 dose of $2 \times 10^{6} \mathrm{cfu} / 20 \mathrm{~g}$ fish. The LD50 bacterial dose required was calculated prior to the experiments using a separate representative sample of fingerlings collected from all families. Hourly observations of mortality for individuals in each family were recorded for up to 
10 days. Liver and/or muscle tissue from 100 early death and 100 late death or surviving animals were collected aseptically from each family and kept in ethanol at $-20^{\circ} \mathrm{C}$ for further DNA extraction. All challenge trials were approved by an Institutional Ethics Committee and performed in accordance with the Indian Government Prevention of Cruelty to Animals Act 1960.

\section{DNA extraction}

Out of the 100 early death and late death/surviving fish in each family, sixty muscle tissue samples from each category were randomly chosen and processed for DNA extraction. Before extraction of DNA, tissue samples (50-100 mg) were rinsed vigorously with $1 \mathrm{ml}$ of PBS and cut into fine pieces with sterile scissors. The minced tissues were processed further for extraction of DNA following a high salt method (http://www.genomics.liv.ac. uk/animal/RESEARCH/ISOLATIO.PDF). The extracted genomic DNA was dissolved in TE buffer $(10 \mathrm{mM}$ Tris $\mathrm{Cl}$, $1 \mathrm{mM}$ EDTA) and stored at $-20^{\circ} \mathrm{C}$. The Phenol Chloroform method described by Sambrook et al. [53] with slight modifications was used to further purify the DNA. The quality of extracted DNA was checked on a $2 \%$ agarose gel in $1 \mathrm{X}$ TBE buffer after electrophoresing at $50 \mathrm{~V}$ for an hour. The concentration and purity of DNA was checked using OD values at 260 and $280 \mathrm{~nm}$. Quantification was achieved using the OD value at $260 \mathrm{~nm}$ measured by a Nanodrop 2000C (Thermo Scientific).

\section{SNP array}

A custom design Illumina iSelect SNP-array was manufactured by Illumina (Illumina, San Diego) containing 6000 candidate SNP loci identified in the de novo assembled transcriptome [9]. SNPs were identified by two numbers separated by an underscore, where the first number was the contig identification number, and the second number was the SNP position in base numbers along the contig length. SNPs chosen for the array had the following characteristics, (i) putative minor allele frequency greater than 0.33 based on sequencing data, (ii) contig lengths greater than 200, (iii) only one SNP per contig, (iv) compatible for the Infinium II Assay (i.e. A/G, $\mathrm{A} / \mathrm{C}, \mathrm{T} / \mathrm{G}$ or $\mathrm{T} / \mathrm{C}$ ), and (v) Assay Design Tool (ADT) scores greater than 0.85 . Samples $(n=1152)$ were genotyped following standard protocols for the iSelect SNParray (Illumina, San Diego). Genotypes were called by first performing automatic clustering using Genome Studio Genotyping Module (V1.9.4), and then by excluding low call rate (low quality) samples, introducing pedigree information and performing manual SNP cluster correction to improve calling where necessary. Manual checking was performed to facilitate the subjective classification of individual marker assays into categories including "failed", "monomorphic", and "SNP" to ensure that only high quantity SNP calls were included in subsequent analysis.

\section{Genomic pedigree checks on the family material used for mapping}

SNP genotypes were grouped based on estimated pairwise relatedness values using the COANCESTRY software package [54] to confirm the parentage assignment of offspring determined at tagging. Following pedigree relationship clustering, the corrected pedigree data (genomic pedigree) was checked for Mendelian inheritance errors using a script written by one of the authors in $\mathrm{R}$ and SNPs or animals showing consistent errors were removed from further analysis.

\section{Linkage map}

A linkage map of the SNP markers was constructed using the full-sib families with available parental genotypes (seven families containing between 114 and 28 offspring) and the software TMAP http://users.math.yale. edu/ dc597/tmap/ [55]. Initially, the program phasing was used to define the marker phases in each family in the pedigree. Subsequently, pedmerge was used to merge these multiple phase-known pedigrees into a single data file. Grouping was used to identify groups of linked markers, with the LOD threshold varied until the number of groups reflected the expected number of chromosomes. Finally, tmap was used to order the markers within each linkage group. Both sex-specific and sex-averaged linkage maps were generated. Graphics of the linkage groups were generated with MAPCHART software [56].

Goodness of fit $\mathrm{G}$ tests were used to test for segregation distortion (proportions differing from segregation ratios expected with Mendelian inheritance) within families for each SNP using a chisq.test function in R. A Bonferonni correction (based on the number of linkage groups examined, which was 25 for L. rohita) was applied to limit experiment-wide error rates associated with multiple testing [57].

\section{Comparison of genome organisation to zebra fish (Danio rerio)}

To annotate the $L$. rohita linkage map with $D$. rerio chromosome locations, protein coding sequences from Danio rerio were downloaded as Fasta sequences from Ensembl (26 July 2013) together with their corresponding chromosome location. BLASTx (version 0.0.1 in Galaxy) was then used to find the single best match between the Danio rerio protein coding sequence and the sequences from the L. rohita contigs which contained mapped SNPs (e-value $<1.00 \mathrm{E}-10)$. 


\section{Genetic parameters, the significance of fixed effects and correlation of traits}

Two alternative phenotypic traits were considered for analysis, (i) hours of survival, which is a continuous trait, and (ii) early death vs. late death or survival (hereafter referred to as dead or alive), which is a binomial trait where animals that were among the first 100 to die from each full-sibling family were classified as dead and animals among the last 100 to die or survive the full duration of the challenge were classified as alive.

An animal model was applied to estimate genetic parameters and the significance of fixed effects (without accounting for SNP genotype). A Markov chain Monte Carlo (MCMC) method using a multi-trait generalised linear mixed effect model (glmm) in a Bayesian estimation framework, with animal breeding value fitted as a random effect, was used for the analysis $\mathrm{R}$ Package, MCMCglmm, [58], http://www.cran.r-project.org. Our main interest was whether tank and/or family should be included as fixed effects in the QTL analysis. All offspring were juveniles when challenged and sex could therefore not be determined. Animal and ID were fitted as random terms. ID was the same as the animal factor, but was used by MCMCglmm to dissociate individual records from the pedigree and give an indication of between individual variance [59]. Therefore the model fitted was as follows,

$$
y=m u+\tan k+\text { family }+ \text { animal }+I D
$$

where $y$ was hours of survival or dead or alive, tank and family were fixed effects, animal and ID were random animal effects and $m u$ represented unknown random residual effects.

All models were run using 300,000 iterations as burnin, 1 million iterations for sampling and a thinning interval of 500. A "plausible" prior assuming weak genetic control (additive genetic variance, permanent environmental variance and residual variance accounting for $0.2,0.1$ and 0.7 ) was used with the smallest possible degree of belief parameter $(n=1)$.

Estimates of additive genetic variance and residual variance were calculated from the modes of the posterior distribution and a Bayesian equivalent of $95 \%$ confidence intervals was obtained by calculating the values of the estimates that bound $95 \%$ of the posterior distributions. Narrow sense heritability $\left(h^{2}\right)$, or the proportion of total phenotypic variance that is additive genetic in origin, was estimated under the model as $V_{A} /\left(V_{A}+V_{E}+V_{e}\right)$ where $V_{A}, V_{E}$ and $V_{e}$ were variance attributed to additive genetic, permanent environmental effects unconstrained by pedigree and residual error effects respectively. In a similar fashion, the additive genetic correlation between the traits hours of survival $(x)$ and dead or alive $(y)$ (or proportion of variance the two traits share due to additive genetic causes, $\left.r_{A x y}\right)$ was estimated as $C O V_{A x y} /$ $\sqrt{\left[V_{A x}^{2} V_{A y}^{2}\right]}$ where $\operatorname{COV}_{\mathrm{Axy}}$ was the genetic covariance for the traits and $\mathrm{V}_{\mathrm{Ax}}$ and $\mathrm{V}_{\mathrm{Ay}}$ were the additive genetic variances attributed to hours of survival and dead or alive traits respectively. Heritability and additive genetic correlation between the traits was considered significant if the 95\% credible interval of the posterior distribution did not span zero.

\section{QTL linkage analysis}

Both the binary dead or alive and continuous hours of survival trait were used for linkage analysis. QTL detection was carried out using a linear regression interval mapping approach in GridQTL [60]. The binary trait dead/alive was analysed together with the number of survival days in the challenge. It has been shown that a binary trait can be analysed using QTL mapping methods intended for quantitative traits, as long as the trait is a threshold trait with an underlying normal distribution [61,62]. Linkage analysis was performed separately for sires and dams of the full-sib families used in the study. $P$-values were calculated for all trait-by-chromosome combinations with the significance of the peak F-statistic (putative QTL) estimated after 10,000 chromosome-wide permutation tests. A QTL was found to be genome-wide significant if the chromosome-wide significance level was less than than $0.002(0.05 / 25)$, a Bonferroni correction based on the number of chromosomes in rohu.

\section{Genome-wide association study}

A genome-wide association study (GWAS) was performed using GenABEL (www.genabel.org) and Plink [http:// pngu.mgh.harvard.edu/purcell/plink/ 59]. First we determined which markers and individuals should be excluded from the GWA analysis using the check.marker function in GenABEL. This function was used to exclude individuals or markers with call rate $<95 \%$, markers with minor allele frequency $<0.24 \%$, individuals with high autosomal heterozygosity (FDR $<1 \%$ ) and individuals with identity by state $\geq 0.95$. Genomic kingship was computed between all pairs of individuals. We performed a pedigree based association analysis where the pedigree is a confounder (where the heritable trait is more similar between close relatives and therefore some degree of association is expected between any genetic marker and any heritable trait). The effect of the confounding pedigree is expected to inflate the resulting null distribution of the chi square test statistic by a constant, lambda. Lambda is a function of the traits heritability and pedigree structure (expressed as a kinship matrix). Two fast tests for genome wide 
association were applied, Family-based Score Test for Association (FASTA, [63]) and Genome-wide Rapid Analysis using Mixed Models And Score test (GRAMMAS, [64]) using the $\mathrm{R}$ package GenABEL (http://www.cran.r-project. org). A mixed polygenic model of inheritance was applied in order to study association in our genetically homogeneous families where the hours of survival or dead or alive traits $(y)$ were modelled as:

$$
y=\mu+f+G+e
$$

where $\mu$ is the intercept, $G$ describes the polygenetic effect (contribution from multiple independently segregating genes all having a small additive effect on the trait), $f$ describes fixed effects (where $f$ was either tank+ family, or where no fixed effects were included in the model) and $e$ describes the random residual effects. The joint distribution of residuals in the pedigree was modelled using a multivariate normal distribution with variance-covariance matrix proportional to the identity matrix. A genomic kingship matrix, generated by calculating the average identity-by-state between individuals in the pedigree (ibs in GenABEL), was used as the relationship matrix for FASTA and GRAMMAS. Both FASTA and GRAMMAS exploit maximum likelihood estimates of the intercept from the polygenic model. Two hundred permutations were used to estimate genome wide significance for the FASTA and GRAMMAS test (downward bias in the estimate of SNP effects are expected).

The QFAM and ASSOC analysis modules in PLINK http://pngu.mgh.harvard.edu/purcell/plink/ [65] were used to perform a linear regression of phenotype on genotype for the traits hours of survival and dead or alive respectively. In the case of QFAM, the module used a permutation procedure to correct for family structure. Association testing was performed within families. Ten thousand permutations per SNP (flipping allele transmission from parent to offspring with 50:50 probability) were applied producing a point-wise estimate of each individual SNPs empirical significance.

GWAS associations with significance at $P<0.001, P<0.01$ and $P<0.05$ levels after Bonferroni correction based on the number of linkage groups (which was 25 for L. rohita) were noted for all tests.

\section{Differential expression in naïve susceptible and resistant line rohu}

Differential transcript expression in selected $A$. hydrophila resistant versus susceptible rohu individuals was checked for some SNP containing contigs using sequence coverage data and methods collected and described in [9]. In brief, selection of the resistant and susceptible line fish by the previous study was made using intra-peritoneal challenge testing of 87 full sibling families (30 siblings per family) with a virulent strain of A. hydrophila. Unchallenged individuals from the 15 highest and 10 lowest ranking families were selected to create the first generation of the resistant and susceptible lines respectively. RNA pools were prepared from liver, intestine, muscle, kidney, spleen and brain tissue samples from 10 resistant and 10 susceptible line fish for comparison. Quantile-based rank normalisation was used to correct for differences between sequencer flow cells or RNA pools [66]. Data were visually represented as Bland-Altman $M A$ scale plots where $M=\log _{2} R-\log _{2} S$ and $A=0.5^{*}\left(\log _{2} R+\log _{2} S\right), R$ and $S$ being average coverage depth for each contig in the resistant and susceptible line pools respectively.

\section{Temporal gene expression changes with A. hydrophila challenge}

Rohu juveniles from the 2008 year class were collected and kept in $700 \mathrm{~L}$ ferro-cement tanks for acclimatization prior to the experiment. A virulent strain of $A$. hydrophila (Ah 15) was isolated from a field outbreak that occurred on a farm at Puri, Odisha, India (Mohanty et al. 2008). Forty eight rohu juveniles (weighing 80-100 g) were challenged intra-peritoneally with live $A$. hydrophila at a dose of $1.5 \times 10^{6} \mathrm{cfu} / \mathrm{g}$ of body weight. Tissue samples from liver, gill and spleen were collected from infected fish at different time periods viz., 1, 3, 6, 12, 24, 48, 72 hours, 7 and 15 days post-infection, along with three non-infected controls, in triplicate after euthanasia with a heavy dose of MS222. The tissue samples were kept in RNAlater (Sigma, USA) and stored at $-20^{\circ} \mathrm{C}$ until RNA extraction. Total RNA was extracted using TRI reagent (Sigma, USA). A total of $1 \mu \mathrm{g}$ of RNA was treated with DNase I (Fermentas, Canada). First strand cDNA was synthesized using M-MLV reverse transcriptase (Genei, India) as per the manufacturer's instructions. qPCR was performed using FastStart Essential DNA Green Master (Roche, Germany) in a Light Cycler 96 (Roche, Germany) using perforin specific primers (forward- 5' GACGCCTACCACAACCT 3' and reverse 5' TTTGCCC TCCTAACTGG 3') designed in Primer Premier Version 5 (Lalitha 2000) from the sequence of contig 113696_50. Briefly, $1 \mu \mathrm{l}$ of synthesized cDNA was used as a template in a total reaction mixture of $10 \mu$ l containing $5 \mu \mathrm{l}$ of $2 \mathrm{X}$ Light cycler SYBR green I mix, $0.5 \mu \mathrm{l}$ of primer pairs (5 pmole) and $3 \mu \mathrm{l}$ of $\mathrm{H}_{2} \mathrm{O}$ provided in the kit. The qPCR programme consisted of pre-denaturation at $95^{\circ} \mathrm{C}$ for $10 \mathrm{~min}$ and 45 cycles of amplification at $95^{\circ} \mathrm{C}$ for $10 \mathrm{sec}, 55^{\circ} \mathrm{C}$ for $10 \mathrm{sec}$, and $72^{\circ} \mathrm{C}$ for $20 \mathrm{sec}$. All reactions were performed simultaneously for each gene with $\beta$-actin [9], in the same plate in triplicates. qPCR specificity was verified by melt curve analysis at a temperature of $95^{\circ} \mathrm{C}$ 
for $10 \mathrm{~s}, 65^{\circ} \mathrm{C}$ for $1 \mathrm{~min}$ and $95^{\circ} \mathrm{C}$ for $1 \mathrm{~min}$. "No-template controls" were included in each run.

The quantification cycle (Cq) values were calculated using a Light Cycler 96 SW 1.1 and the data was exported. $\mathrm{N}$-fold differential expression was calculated using the comparative Cq method [67]. The Cq value of the gene for each cDNA was subtracted from its respective $\mathrm{Cq}$ value of $\beta$-actin to give a $\Delta C q$ value. Since the samples for each time period were taken in triplicate, an average of the $\Delta C q$ values was obtained. Further, $\Delta \Delta C q$ was calculated by subtracting $\Delta \mathrm{Cq}$ for post-infection samples from the $\Delta \mathrm{Cq}$ value of the calibrator $(0 \mathrm{~h}$ control). Fold difference was calculated as $2^{-\Delta \Delta C q}$. Mean fold differences and standard errors were calculated. Differences between the temporal mean values of one gene in an organ was analysed using one-way ANOVA followed by Duncan's multiple range tests, with values $P<0.05$ considered as significantly different.

\section{Availability of supporting data}

All assembled transcriptome reads are available through GEO Series accession number GSE27994 (http://www. ncbi.nlm.nih.gov/geo/query/acc.cgi?acc=GSE27994). Other supporting data (SNP sequence, annotation and correspondence with chromosome regions in the zebra fish) is included in the additional files section.

\section{Additional files}

Additional file 1: Consensus sex averaged transcribed gene linkage map for Labeo rohita. SNP marker names (contig number followed by position in base pairs) are shown to the right of each linkage group while position (in Kosambi cM relative to the upper marker in the group) is shown to the left.

Additional file 2: Sequence and annotation of contigs containing mapped SNPs (MS-excel file). LG, linkage group. CM, position on linkage group in centimorgans. GeneID, closest SNP homology from BLAST. snpA and snpB, alternative alleles for SNP. SequenomNot, contig sequence showing alternative SNP allele in square brackets.

Additional file 3: Correspondence of annotated SNPs mapped in L. rohita to peptides and chromosome regions in the zebra fish (Danio rerio) genome (MS-excel file).

Additional file 4: Figure S1. Frequency of hour's survival after challenge with A. hydrophila within L. rohita families A-U.

Competing interests

The authors declare that they have no competing interests.

\section{Authors' contributions}

$\mathrm{NR}$, MB, PKS, and KDM designed the research; PKS, KDM, JNS, SD, YM, PD, NR, and $\mathrm{MB}$ performed the research; $\mathrm{NR}$ and $\mathrm{MB}$ contributed new analytic tools; $N R, M K, M A$ and MB analysed data; and NR, MB, MK and PKS wrote the paper. All authors read and approved the final manuscript.

\section{Acknowledgements}

The authors are thankful to the Norwegian Research Council, Department of Biotechnology of India and Indian Council of Agricultural Research for funding this project (project 183833).

\section{Author details}

'Breeding and Genetics, Nofima, PO Box 5010, 1432 Ås, Norway. ${ }^{2}$ Central Institute of Freshwater Aquaculture, Kausalyaganga, Bhubaneswar, India. ${ }^{3}$ Biological Sciences, Flinders University, Bedford Park, Australia. ${ }^{4}$ Centre for Integrative Genetics, University of Life Sciences, Ås, Norway.

Received: 27 December 2013 Accepted: 17 June 2014

Published: 30 June 2014

\section{References}

1. Food and Agriculture Organisation of the United Nations: The state of world fisheries and aquaculture. Rome: FAO; 2010.

2. Das Mahapatra K, Jana RK, Saha JN, Gjerde B, Sarangi N: Lessons from the breeding program of rohu. In Development of aquatic animal genetic improvement and dissemination programs: current status and action plans. Edited by Ponzoni RW, Acosta BO, Ponniah AG. Penang, Malaysia: World Fish Centre; 2006:34-40.

3. Jeney Z, Jeney G: Recent achievements in studies on diseases of common carp (Cyprinus carpio L). Aquaculture 1995, 129(1-4):397-420.

4. Das Mahapatra K, Gjerde B, Sahoo PK, Saha JN, Barat A, Sahoo M, Mohanty BR, Odegard J, Rye M, Salte R: Genetic variations in survival of rohu carp (Labeo rohita, Hamilton) after Aeromonas hydrophila infection in challenge tests. Aquaculture 2008, 279(1-4):29-34.

5. Sahoo PK, Rauta PR, Mohanty BR, Mahapatra KD, Saha JN, Rye M, Eknath AE: Selection for improved resistance to Aeromonas hydrophila in Indian major carp Labeo rohita: Survival and innate immune responses in first generation of resistant and susceptible lines. Fish Shellfish Immunol 2011, 31(3):432-438.

6. Moen T, Baranski M, Sonesson A, Kjoglum S: Confirmation and fine-mapping of a major QTL for resistance to infectious pancreatic necrosis in Atlantic salmon (Salmo salar): population-level associations between markers and trait. BMC Genomics 2009, 10(1):368.

7. Heng JF, Su JG, Huang T, Dong J, Chen LJ: The polymorphism and haplotype of TLR3 gene in grass carp (Ctenopharyngodon idella) and their associations with susceptibility/resistance to grass carp reovirus. Fish Shellfish Immunol 2011, 30(1):45-50.

8. Houston RD, Guy DR, Hamilton A, Ralph J, Spreckley N, Taggart JB, McAndrew BJ, Haley CS, Bishop SC: Detection of major QTL affecting resistance to Infectious Pancreatic Necrosis (IPN) in a commercial atlantic salmon population. In Proceedings of the 8th World Congress on Genetics Applied to Livestock Production, Belo Horizonte, Minas Gerais, Brazil, 13-18 August, 2006. Minas Gerais, Brazil: Instituto Prociencia; 2006:15-02.

9. Robinson NA, Sahoo PK, Baranski M, Das Mahapatra K, Saha JN, Das S, Mishra Y, Das P, Barman HK, Eknath AE: Expressed sequences and polymorphisms in rohu carp (Labeo rohita, Hamilton) revealed by mRNA-seq. Mar Biotechnol (NY) 2012, 14:620-633. 14

10. Sahoo PK, Das S, Das Mahapatra K, Saha JN, Baranski M, Odegard J, Robinson N: Characterization of the ceruloplasmin gene and its potential role as an indirect marker for selection to Aeromonas hydrophila resistance in rohu, Labeo rohita. Fish Shellfish Immunol 2013, 34(5):1325-1334

11. Wang GL, Li XL, Li JL: Significant association between SNPs in the superoxide dismutase 3, extracellular (SOD3) gene and resistance to Aeromonas hydrophila in the freshwater mussel Hyriopsis cumingii. Anim Genet 2013, 44:693-702.

12. Zhang S, Reddy PVGK: On the comparative Karyomorphology of the three Indian major carps, Catla catla (Hamilton), Labeo rohita (Hamilton) and Cirrhinus mrigala (Hamilton). Aquaculture 1991, 97:7-12.

13. Zheng XH, Kuang YY, Lv WH, Cao DC, Zhang XF, Li C, Lu CY, Sun XW: A consensus linkage map of common carp (Cyprinus carpio L.) to compare the distribution and variation of QTLs associated with growth traits. Sci China Life Sci 2013, 56(4):351-359.

14. Jin $S B$, Zhang XF, Jia ZY, Fu HT, Zheng XH, Sun XW: Genetic linkage mapping and genetic analysis of QTL related to eye cross and eye diameter in common carp (Cyprinus carpio L.) using microsatellites and SNPs. Aquaculture 2012, 358:176-182.

15. Zhang Y, Xu P, Lu CY, Kuang YY, Zhang XF, Cao DC, Li C, Chang YM, Hou N, Li HD, Wang S, Sun XW: Genetic Linkage Mapping and Analysis of Muscle Fiber-Related QTLs in Common Carp (Cyprinus carpio L.). Mar Biotechnol (NY) 2011, 13(3):376-392 
16. Cheng L, Liu L, Yu X, Wang D, Tong J: A linkage map of common carp (Cyprinus carpio) based on AFLP and microsatellite markers. Anim Genet 2010, 41(2):191-198.

17. Patel A, Das P, Barat A, Sarangi N: Estimation of genome size of Indian major carps Labeo rohita (Hamilton), Cirrhinus mrigala (Hamilton) and Labeo calbasu (Hamilton) by Feulgen microdensitometry method. Indian J Fish 2009, 56:65-67.

18. Briggs JC: The biogeography of otophysan fishes (Ostariophysi: Otophysi): a new appraisal. J Biogeogr 2005, 32(2):287-294.

19. Oudshoorn D, Versteeg GA, Kikkert M: Regulation of the innate immune system by ubiquitin and ubiquitin-like modifiers. Cytokine Growth Factor Rev 2012, 23(6):273-282.

20. Peart J, Lu R, Sadanandom A, Malcuit I, Moffett P, Brice DC, Schauser L, Jaggard DAW, Xiao SY, Coleman MJ, Dow M, Jones JDG, Shirasu K, Baulcombe DC: Ubiquitin ligase-associated protein SGT1 is required for host and nonhost disease resistance in plants. Proc Natl Acad Sci U S A 2002, 99(16):10865-10869.

21. Goldberg AL: Functions of the proteasome: from protein degradation and immune surveillance to cancer therapy. Biochem Soc Trans 2007 35:12-17.

22. Rock KL, York IA, Saric T, Goldberg AL: Protein degradation and the generation of MHC class I-presented peptides. In Advances in Immunology, Vol 80. Edited by Dixon FJ. San Diego: Elsevier Academic Press Inc; 2002:1-70. vol. 80.

23. Klausner RD, Samelson LE: T cell antigen receptor activation pathways: the tyrosine kinase connection. Cell 1991, 64(5):875-878.

24. Øvergård AC, Nerland AH, Patel S: Cloning, characterization, and expression pattern of Atlantic halibut (Hippoglossus hippoglossus L.) CD4-2, Lck, and ZAP-70. Fish Shellfish Immunol 2010, 29(6):987-997.

25. Molina TJ, Kishihara K, Siderovskid DP, van Ewijk W, Narendran A, Timms E, Wakeham A, Paige CJ, Hartmann KU, Veillette A, Davidson D, Mak TW: Profound block in thymocyte development in mice lacking p56lck. Nature 1992, 357(6374):161-164.

26. Brenner S, Venkatesh B, Yap WH, Chou CF, Tay A, Ponniah S, Wang Y, Tan $\mathrm{YH}$ : Conserved regulation of the lymphocyte-specific expression of Ick in the Fugu and mammals. Proc Natl Acad Sci U S A 2002, 99(5):2936-2941.

27. Nikolich-Žugich J, Fremont DH, Miley MJ, Messaoudi I: The role of mhc polymorphism in anti-microbial resistance. Microbes Infect 2004, 6:501-512.

28. Malmstrøm M, Jentoft S, Gregers TF, Jakobsen KS: Unraveling the evolution of the Atlantic cod's (Gadus morhua L.) alternative immune strategy. PLoS One 2013, 8(9):e74004

29. Grimholt U, Larsen S, Nordmo R, Midtlyng P, Kjoeglum S, Storset A, Saeb S, Stet RJM: MHC polymorphism and disease resistance in Atlantic salmon (Salmo salar); facing pathogens with single expressed major histocompatibility class I and class II loci. Immunogenetics 2003, 55(4):210-219.

30. Imai E, Ishikawa J, Moritomo T, Tomana M: Characterisation of T cell antigen receptor alpha chain isotypes in the common carp. Fish Shellfish Immunol 2005, 19(3):205-216.

31. Nithikulworawong N, Yakupitiyage A, Rakshit SK, Srisapoome P: Molecular characterization and increased expression of the Nile tilapia, Oreochromis niloticus (L.), T-cell receptor beta chain in response to Streptococcus agalactiae infection. J Fish Dis 2012, 35(5):343-358.

32. Kinjo $Y$, Kitano N, Kronenberg M: The role of invariant natural killer T cells in microbial immunity. J Infect Chemother 2013, 19(4):560-570.

33. Radons J, Multhoff G: Immunostimulatory functions of membrane-bound and exported heat shock protein 70. Exerc Immunol Rev 2005, 11:17-33.

34. Saxena A, Banasavadi-Siddegowda YK, Fan Y, Bhattacharya S, Roy G, Giovannucci DR, Frizzell RA, Wang X: Human Heat Shock Protein 105/ 110 kDa (Hsp105/110) Regulates Biogenesis and Quality Control of Misfolded Cystic Fibrosis Transmembrane Conductance Regulator at Multiple Levels. J Biol Chem 2012, 287(23):19158-19170.

35. Quintana FJ, Cohen IR: The HSP60 immune system network. Trends Immunol 2011, 32(2):89-95.

36. van der Marel M, Caspari N, Neuhaus H, Meyer W, Enss ML, Steinhagen D: Changes in skin mucus of common carp, Cyprinus carpio L., after exposure to water with a high bacterial load. J Fish Dis 2010, 33(5):431-439.

37. Schroers V, van der Marel M, Neuhaus H, Steinhagen D: Changes of intestinal mucus glycoproteins after peroral application of Aeromonas hydrophila to common carp (Cyprinus carpio). Aquaculture 2009, 288(3-4):184-189.
38. Fock WL, Chen CL, Lam TJ, Sin YM: Roles of an endogenous serum lectin in the immune protection of blue gourami, Trichogaster trichopterus (Pallus) against Aeromonas hydrophila. Fish Shellfish Immunol 2001, 11(2):101-113

39. Dutta S, Sinha B, Bhattacharya B, Chatterjee B, Mazumder S: Characterization of a galactose binding serum lectin from the Indian catfish, Clarias batrachus: Possible involvement of fish lectins in differential recognition of pathogens. Com Biochem Physiol C Toxicol Pharmacol 2005, 141(1):76-84.

40. Young KM, Russell S, Smith M, Huber P, Ostland VE, Brooks AS, Hayes MA, Lumsden JS: Bacterial-binding activity and plasma concentration of ladderlectin in rainbow trout (Oncorhynchus mykiss). Fish Shellfish Immunol 2007, 23(2):305-315.

41. Merino-Contreras ML, Guzman-Murillo MA, Ruiz-Bustos E, Romero MJ, Cadena-Roa MA, Ascencio F: Mucosal immune response of spotted sand bass Paralabrax maculatofasciatus (Steindachner, 1868) orally immunised with an extracellular lectin of Aeromonas veronii. Fish Shellfish Immunol 2001, 11(2):115-126.

42. Otipoby $\mathrm{KL}$, Draves $\mathrm{KE}$, Clark EA: CD22 regulates $\mathrm{B}$ cell receptor-mediated signals via two domains that independently recruit Grb2 and SHP-1. J Biol Chem 2001, 276:44315-44322

43. Lajaunias F, Nitschke L, Moll T, Martinez-Soria E, Semac I, Chicheportiche $Y$, Parkhouse RM, Izui S: Differentially regulated expression and function of CD22 in activated B-1 and B-2 lymphocytes. J Immunol 2002, 168:6078-6083

44. Satone H, Oshima Y, Shimasaki Y, Tawaratsumida T, Oba Y, Takahashi E Kitano T, Kawabata SI, Kakuta Y, Honjo T: Tributyltin-binding protein type 1 has a distinctive lipocalin-like structure and is involved in the excretion of tributyltin in Japanese flounder, Paralichthys olivaceus. Aquat Toxicol 2008, 90(4):292-299.

45. Millan A, Gomez-Tato A, Fernandez C, Pardo BG, Alvarez-Dios JA, Calaza M, Bouza C, Vazquez M, Cabaleiro S, Martinez P: Design and Performance of a Turbot (Scophthalmus maximus) Oligo-microarray Based on ESTs from Immune Tissues. Mar Biotechnol (NY) 2010, 12(4):452-465.

46. Walport MJ: Complement: First of two parts. N Engl J Med 2001, 344:1058-1066

47. Kuijpers TW, Nguyen M, Hopman CTP, Nieuwenhuys E, Dewald G, Lankester AC, Roos A, van der Ende A, Fijen C, de Boer M: Complement factor 7 gene mutations in relation to meningococcal infection and clinical recurrence of meningococcal disease. Mol Immunol 2010, 47(4):671-677.

48. Kondos SC, Hatfaludi T, Voskoboinik I, Trapani JA, Law RHP, Whisstock JC, Dunstone MA: The structure and function of mammalian membraneattack complex/perforin-like proteins. Tissue Antigens 2010, 76(5):341-351.

49. Chiravuri M, Schmitz T, Yardley K, Underwood R, Dayal Y, Huber BT: A novel apoptotic pathway in quiescent lymphocytes identified by inhibition of a post-proline cleaving aminodipeptidase: A candidate target protease, quiescent cell proline dipeptidase. J Immunol 1999, 163(6):3092-3099.

50. Ødegård J, Olesen I, Dixon P, Jeney Z, Nielsen HM, Way K, Joiner C, Jeney G, Ardo L, Ronyai A, Gjerde B: Genetic analysis of common carp (Cyprinus carpio) strains: II: Resistance to koi herpesvirus and Aeromonas hydrophila and their relationship with pond survival. Aquaculture 2010, 304(1-4):7-13.

51. Gjerde B, Reddy P, Mahapatra KD, Saha JN, Jana RK, Meher PK, Sahoo M, Lenka S, Govindassamy P, Rye M: Growth and survival in two complete diallele crosses with five stocks of Rohu carp (Labeo rohita). Aquaculture 2002, 209(1-4):103-115.

52. Reddy P, Gjerde B, Tripathi SD, Jana RK, Mahapatra KD, Gupta SD, Saha JN, Sahoo M, Lenka S, Govindassamy P, Rye M, Gjedrem T: Growth and survival of six stocks of rohu (Labeo rohita, Hamilton) in mono and polyculture production systems. Aquaculture 2002, 203(3-4):239-250.

53. Sambrook J, Fritsch EF, Maniatis T: Molecular Cloning: A Laboratory Manual (2nd edition). New York: Cold Spring Harbor Laboratory Press; 1989.

54. Wang J: COANCESTRY: A program for simulating, estimating and analysing relatedness and inbreeding coefficients. Mol Ecol Resour 2011, 11(1):141-145

55. Cartwright DA, Troggio M, Velasco R, Gutin A: Genetic mapping in the presence of genotyping errors. Genetics 2007, 176(4):2521-2527.

56. Voorrips RE: MAPCHART: Software for the graphical presentation of linkage maps and QTLs. J Hered 2002, 93:77-78

57. Woram RA, McGowan C, Stout JA, Gharbi K, Ferguson MM, Hoyheim B, Davidson EA, Davidson WS, Rexroad C, Danzmann RG: A genetic linkage 
map for Arctic char (Salvelinus alpinus): evidence for higher recombination rates and segregation distortion in hybrid versus pure strain mapping parents. Genome 2004, 47(2):304-315.

58. Hadfield JD: MCMC methods for Multi-response Generalised Linear Mixed Models: The MCMCgImm R Package. J Stat Softw 2010, 33:1-22.

59. Wilson AJ, Reale D, Clements MN, Morrissey MM, Postma E, Walling CA, Kruuk LEB, Nussey DH: An ecologists guide to the animal model. J Anim Ecol 2009, 79:13-26.

60. Seaton G, Hernandez J, Grunchec JA, White I, Allen J, De Koning DJ, Wei W, Berry D, Haley C, Knott S: GridQTL: A Grid Portal for QTL Mapping of Compute Intensive Datasets. In Proceedings of the 8th World Congress on Genetics Applied to Livestock Production: 2006. Brazil: Belo Horizonte; 2006.

61. Visscher PM, Thompson R, Haley CS: Confidence intervals in QTL mapping by bootstrapping. Genetics 1996, 143:1013-1020.

62. Kadarmideen HN, Dekkers JCM: Generalized marker regression and interval QTL mapping methods for binary traits in half-sib family designs. J Anim Breed Genet 2001, 118(5):297-309.

63. Chen W-M, Abecasis GR: Family-based association tests for genomewide association scans. Am J Hum Genet 2007, 81:913-926.

64. Amin N, van Duijn CM, Aulchenko YS: A genomic back-ground based method for association analysis in related individuals. PloS One 2007, 2:e1274.

65. Purcell S, Neale B, Todd-Brown K, Thomas L, Ferreira MAR, Bender D, Maller J, Sklar P, de Bakker PIW, Daly MJ, Sham PC: PLINK: a toolset for whole-genome association and population-based linkage analysis. Am J Hum Genet 2007, 81:559-575.

66. Bullard JH, Purdom E, Hansen KD, Dudoit S: Evaluation of statistical methods for normalisation and differential expression in mRNA-Seq experiments. BMC Bioinformatics 2010, 11:94.

67. Livak KJ, Schmittgen TD: Analysis of Relative Gene Expression Data Using Real-Time Quantitative PCR and the 2-[Delta] [Delta] CT Method. Methods 2001, 25(4):402-408.

doi:10.1186/1471-2164-15-54

Cite this article as: Robinson et al: A linkage map of transcribed single nucleotide polymorphisms in rohu (Labeo rohita) and QTL associated with resistance to Aeromonas hydrophila. BMC Genomics 2014 15:541.

\section{Submit your next manuscript to BioMed Central and take full advantage of:}

- Convenient online submission

- Thorough peer review

- No space constraints or color figure charges

- Immediate publication on acceptance

- Inclusion in PubMed, CAS, Scopus and Google Scholar

- Research which is freely available for redistribution 